\title{
Empirical relationships between AIRSAR backscatter and LiDAR-derived forest biomass, Queensland, Australia
}

\author{
Richard M. Lucas ${ }^{\mathrm{a}, *}$, Natasha Cronin ${ }^{\mathrm{b}}$, Alex Lee $^{\mathrm{c}}$, Mahta Moghaddam ${ }^{\mathrm{d}}$, \\ Christian Witte ${ }^{\mathrm{b}}$, Phil Tickle ${ }^{\mathrm{e}}$ \\ a Institute of Geography and Earth Sciences, the University of Wales, Aberystwyth, Ceredigion, SY23 3DB, United Kingdom \\ ${ }^{\mathrm{b}}$ Climate Impacts and Natural Resource Systems, Queensland Department of Natural Resources, Mines and Energy, \\ 80 Meiers Road, Indooroopilly, 4068, QLD, Australia \\ ${ }^{c}$ School of Resources, Environment and Society, Australian National University, Canberra, ACT, Australia \\ ${ }^{\mathrm{d}}$ Electrical Engineering and Computer Science Department, University of Michigan, 3226 EECS, 1301 Beal Ave., Ann Arbor, MI 48109-2122, USA \\ ${ }^{\mathrm{e}}$ Geoscience Australia GPO Box 738, Canberra, ACT 2601, Australia
}

Received 22 June 2005; received in revised form 25 September 2005; accepted 15 October 2005

\begin{abstract}
To evaluate the use of multi-frequency, polarimetric Synthetic Aperture Radar (SAR) data for quantifying the above ground biomass (AGB) of open forests and woodlands, NASA JPL AIRSAR (POLSAR) data were acquired over a $37 \times 60 \mathrm{~km}$ area west of Injune, central Queensland, Australia. From field measurements recorded within $3250 \times 50 \mathrm{~m}$ plots, AGB was estimated by applying species-specific allometric equations to stand measurements. AGB was then scaled-up to the larger area using relationships established with Light Detection and Ranging (LiDAR) data acquired over 150 (10 columns, 15 rows) $500 \times 150$ m cells (or Primary Sampling Units, PSUs) spaced $4 \times 4$ km apart in the north- and east-west directions. Large-scale $(1: 4000)$ stereo aerial photographs were also acquired for each PSU to assess species composition. Based on the LiDAR extrapolations, the median AGB for the PSU grid was $82 \mathrm{Mg} \mathrm{ha}^{-1}$ (maximum $164 \mathrm{Mg} \mathrm{ha}^{-1}$ ), with the higher levels associated with forests containing a high proportion of Angophora and Callitris species. Empirical relationships between AGB and SAR backscatter confirmed that C-, L- and P-band saturated at different levels and revealed a greater strength in the relationship at higher incidence angles and a larger dynamic range and consistency of relationships at $\mathrm{HV}$ polarizations. A higher level of saturation (above $\sim 50 \mathrm{Mg} \mathrm{ha}^{-1}$ ) was observed at C-band HV compared to that reported for closed forests which was attributable to a link between foliage projected cover (FPC) and AGB. The study concludes that L-band $\mathrm{HV}$ backscatter data acquired at incidence angles approaching or exceeding $45^{\circ}$ are best suited for estimating the AGB up to the saturation level of $\sim 80-85 \mathrm{Mg} \mathrm{ha}^{-1}$. For regional mapping of biomass below the level of saturation, the use of the Japanese Space Exploration Agency (JAXA) Advanced Land Observing Satellite (ALOS) Phase Arrayed L-band SAR (PALSAR) is advocated.
\end{abstract}

(C) 2005 Elsevier Inc. All rights reserved.

Keywords: Synthetic aperture radar; Forests; Biomass; Saturation; Incidence angle; Polarization

\section{Introduction}

Within Australia, information relating to the biomass of forests is required to support regional calculation of carbon budgets (Barrett et al., 2001; Henry et al., 2002). Combined with information on structure, estimates of forest biomass also assist the sustainable utilization of forests and conservation of

\footnotetext{
* Corresponding author. Tel.: +44 1970 622612; fax: +44 1970622659.

E-mail addresses: rml@aber.ac.uk (R.M. Lucas),

Natasha.Cronin@nrm.qld.gov.au (N. Cronin), Alex.Lee@anu.edu.au (A. Lee), mmoghadd@eecs.umich.edu (M. Moghaddam).
}

biodiversity. Such estimates, which focus largely on above ground biomass (AGB), are often obtained by assigning an AGB estimate (typically obtained by applying allometric equations to forest inventory data; Burrows et al., 2000; Le Toan et al., 2004) to broad vegetation categories mapped through existing inventory programmes (Lucas et al., 2000). In such cases, data from relatively few field plots are available compared to the number of unit areas for which AGB estimates need to be provided and the heterogeneity of AGB within forests is not adequately captured. An alternative is to map AGB from optical remote sensing data or derived measures (e.g., canopy cover, vegetation indices; e.g., Foody et al., 
2001), although only indirect estimates are provided as the three-dimensional structure can only be inferred. Although the integration of productivity models with remote sensing data provides a useful approach (Turner et al., 1999), the complex dynamics of biomass accumulation and turnover within mixed species forests and the impacts of land management practices (Lucas et al., 2002) are not well considered. Although all of these options are currently utilized across the world, the routine provision of biomass estimates at the sub-hectare level, over large areas and to an acceptable level of accuracy $(\sim>85 \%$ overall with no class being less than $70 \%$; Tomlinson et al., 1999) remains a significant challenge for many countries.

In the past 15 years, studies (e.g., Dobson et al., 1992; Le Toan et al., 1992; Ranson and Sun, 1994; Austin et al., 2003; Imhoff, 1995a,b; Luckman et al., 1997; Rignot et al., 1994) worldwide have illustrated the potential of Synthetic Aperture Radar (SAR) data for quantifying AGB, particularly at lower frequencies (e.g., L-band and P-band; Rosenqvist et al., 2003; dos Santos et al., 2003). However, perceived inconsistencies in the relationships between AGB and SAR data (Lucas et al., 2000) within and between regions have resulted in limited uptake of these data for operational mapping purposes. Such inconsistencies have resulted partly from the reliance on plotbased estimates of AGB for establishing relationships as these do not fully allow complicating factors, such as the influence of radar parameters (e.g., incidence angle) or forest attributes (e.g., structural differences between tree species, growth stages or stands), to be identified and therefore fully understood.

An opportunity to better evaluate the potential of SAR for quantifying AGB in Australia arose with the NASA PACRIM II AIRSAR mission in 2000. During this mission, AIRSAR over-flights were scheduled (in September) for an area west of the township of Injune in central Queensland. At the same time, an extensive field campaign involving plot-based forest inventory and destructive harvesting of key tree species was undertaken together with an airborne campaign aimed at acquiring supportive large scale $(1: 4000)$ stereo aerial photography (LSP) together with Light Detection and Ranging (LiDAR) and hyperspectral Compact Airborne Spectrographic Imager (CASI) data (Lucas et al., 2001, 2004).

In this paper, we report the outcomes of the research which aimed to:

- Develop approaches for scaling-up plot-based estimates of AGB to the larger area using fine $(<1 \mathrm{~m})$ spatial resolution LiDAR data.

- Use these estimates, with community information from LSP, to evaluate the potential of polarimetric Synthetic Aperture Radar (SAR) for quantifying the AGB of forests typical to large areas of Queensland.

The research was undertaken in the knowledge that the Japanese Advanced Land Observing Satellite (ALOS) Phase Arrayed L-band SAR (PALSAR) would be acquiring full and dual ( $\mathrm{HH}$ and $\mathrm{HV}$ ) polarimetric L-band data over the
Australian continent from 2006. The integration of CASI data for interpreting SAR is reported in forthcoming papers.

\section{Study area}

The study focused on a $37 \times 60 \mathrm{~km}$ area of forest and agricultural land near Injune (Latitude $-25^{\circ} 32^{\prime}$, Longitude $147^{\circ} 32$ ), which is located in the Southern Brigalow Belt (SBB), a biogeographic region of east and central Queensland (Fig. 1). These forests, which are defined as all woody vegetation with a top height equal to or greater than $2 \mathrm{~m}$ above the ground, are classified as being either open forest (51-80\% crown cover (CC) equivalent to $30-70 \%$ Foliage Projected Cover or FPC) or woodlands $(20-50 \%$ CC or $10-$ $30 \%$ FPC; Carnahan, 1990; Dowling \& Accad, 2003). In terms of their structure and also biomass, these forests are typical to over $70 \%$ of Australia's national estate (BRS, 2003).

Although a wide range of tree species occur within the study area, several dominate with their distribution linked closely to topography and soils. Altitude ranges from $437-$ $850 \mathrm{~m}$ (range $413 \mathrm{~m}$ ), but the terrain is generally flat with some undulating hills, plateaux and plains in the northwest, centre and south. A few isolated eroded volcanic outcrops account for the higher elevations observed. Using a $25 \mathrm{~m}$ Digital Elevation Model (DEM), 50\% and 77\% of the study area supported a slope of $<27^{\circ}$ or $34^{\circ}$, respectively. Within this topographic setting, forests dominated by White Cypress Pine (Callitris glaucophylla) occur mainly on the sandy hills, whilst those dominated by Poplar Box (Eucalyptus populnea), Silver Leaved Ironbark (E. melanaphloia) and Brigalow (Acacia Harpophylla) occupy the more alluvial clays in the valleys. A characteristic of the vegetation is the scattered presence of large emergent trees with expansive crowns (e.g., Smooth Barked Apple or Angophora Leiocarpa; Tumbledown Red Gum or Eucalyptus dealbata var. chlorocada). Species associations are commonplace. The mean annual rainfall is approximately $635 \mathrm{~mm}$ year $^{-1}$, although is variable with most recorded between December and February (summer) and the mean annual maximum temperature is $27{ }^{\circ} \mathrm{C}$ (Bureau of Meteorology, 2004).

The forest structure is complex due to the presence of stands at various stages of regeneration and degradation, although are often dominated by only a few species. Large areas of forest are grazed by cattle whilst others have been cleared, through various techniques including stem injection and chaining, largely to facilitate establishment of cattle pasture and cropping. Regeneration on cleared areas is frequent, with many areas dominated by A. harpophylla. Approximately $25 \%$ of the area is State Forest, within which C. glaucophylla is selectively harvested, whilst the remainder is occupied by leasehold properties. Wildfires are not regular but when they occur, they alter the species composition within the forests, particularly as some species (particularly C. glaucophylla) are less resistant to fire than others (Harris et al., 2003). Throughout the area, dense thickets of vegetation (including locked up stands of $C$. glaucophylla) are evident and, as with large parts of 


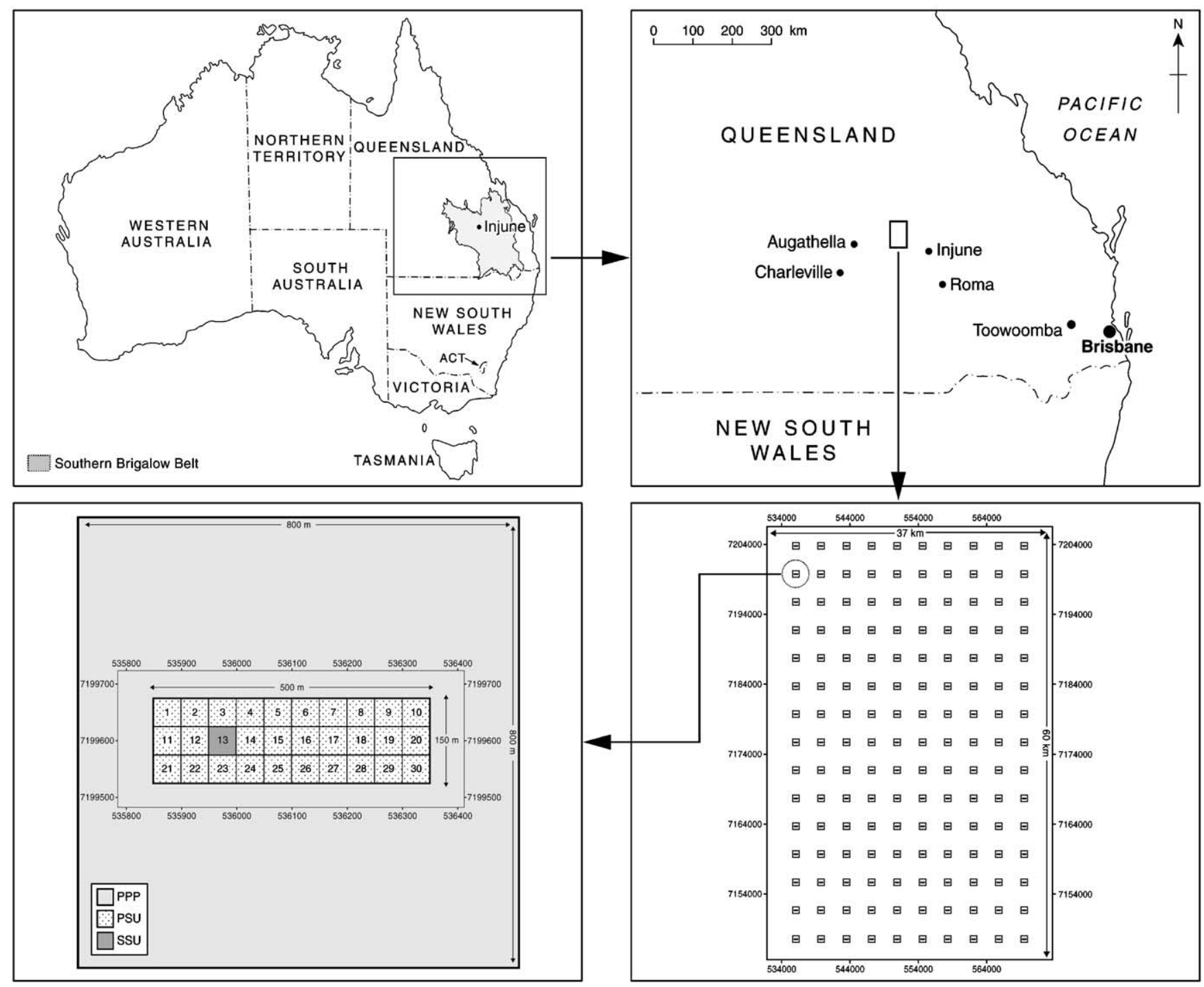

Fig. 1. The location of the Southern Brigalow Belt (Grey) and the Injune study area and the layout of the 150 PPP and PSUs and the contained SSU (30 per PSU). Note that PPP/PSU 11 (of 150) and SSU 13 (of 30) are highlighted.

Queensland, woody thickening may be occurring (Burrows et al., 2002). Clusters of large Angophoras supporting a high biomass are commonplace.

\section{Data collection}

\subsection{Sampling design}

An appropriate sampling scheme was necessary to facilitate scaling-up of plot-based estimates of forest attributes (e.g., species composition, structure and AGB) to the larger area using aerial photography and LiDAR and subsequent establishment of relationships with SAR data. In designing the scheme, the following factors were considered. First, knowledge of the species composition, structural diversity and biomass of the woodlands was relatively limited, particularly given the rapid rate of clearing in recent years and the lack of comprehensive and up-to-date vegetation maps. This lack of prior knowledge limited the implementation of a stratified sampling approach. Second, the basic sampling unit was necessarily constrained by the extent of coverage able to be provided by 1:4000 LSP, but also by the area of overlap ( $\sim 920$ $\mathrm{m}$ width and $150 \mathrm{~m}$ overlap) within stereo pairs, which was required for stereographic interpretation. Constraints were also imposed by the characteristics of other observing sensors (LiDAR but also Compact Airborne Spectrographic Imager or CASI) and their supporting platforms (light aircraft, helicopters), particularly in terms of swath width, flying height, direction of flight and flying times. Third, there was a requirement for unbiased sampling.

Based on these considerations, a sampling scheme for the $37 \times 60 \mathrm{~km}$ study area was implemented (Lucas et al., 2004; Fig. 1) which allowed the acquisition of LSP across a systematic grid of 150 (10 columns and 15 rows) $500 \times 150$ $\mathrm{m}$ Primary Sampling Units (PSUs), with each PSU centre located $4 \mathrm{~km}$ apart in the north- and east-west directions. Each PSU was positioned to encompass the area of LSP overlap and the orthogonal orientation optimised sampling by LiDAR 
(east-west direction) and LSP (north-south direction). The scheme also divided each of the 150 PSUs into 30 Secondary Sampling Units (SSU), $50 \times 50 \mathrm{~m}(0.25 \mathrm{ha})$ in dimension and numbered progressively by row from top left (1) to bottom right (30). Based on this scheme, the equivalent of 45000.25 ha (i.e., 1125 ha) was contained within the PSU grid, which represented $0.46 \%$ of the 220,000 ha study area.

\subsection{Acquisition and processing of LSP}

For each of the 150 PSUs, and using pre-defined coordinates, 1:4000 LSP (in negative format) were acquired on the 11th July 2000 by QASCO Surveys Pty. Ltd. on behalf of the Queensland Department of Natural Resources (QDNR) Landcare Centre. Photographs were taken using an RC20 large format photographic camera from late morning to mid afternoon. The effective swath width was $920 \mathrm{~m}$ with a $60 \%$ (50 ha) overlap corresponding to the PSU. For each photo principle point, GPS coordinates were recorded with a nominal precision of $\pm 20 \mathrm{~m}$ absolute location. As 150 PSUs were sampled, 300 frames of photographs were obtained. Each pair of frames was referred to as a Primary Photo Plot (PPP; Fig. 1) and together, these covered an area of $800 \times 800 \mathrm{~m}$ (64 ha).

Following delivery of the 150 hard copy stereo pairs, the main vegetation communities were differentiated and delineated manually within the area of stereo overlap by a trained photogrammetrist and described in terms of their species composition, height, cover and disturbance (Jones, 2000). Using this information, PSUs representing the main vegetation types and regeneration stages were identified. From these, the PSUs assigned for subsequent field survey were selected, with the final selection based primarily on criteria relating to accessibility.

\subsection{Field data collection}

During August 2000, field data were collected from 32 $50 \times 50 \mathrm{~m}$ SSUs located within twelve of the 150 PSUs such that the main vegetation types and regeneration stages were represented. For 30 of these SSUs, field data were collected from $50 \times 50 \mathrm{~m}$ plots and included the locations of all trees $>5$ $\mathrm{cm}$ diameter $($ at $130 \mathrm{~cm})$ and their diameter at $30 \mathrm{~cm}\left(D_{30}\right)$ and $130 \mathrm{~cm}\left(D_{130}\right)$ above ground level, their height $(H)$ and crown dimensions $(x, y$ and $z$ ). Each tree measured was identified to species. Trees $<5 \mathrm{~cm}$ diameter were recorded in five $10 \times 10$ plots located in the centre of each PSU and along the diagonals, $10 \mathrm{~m}$ distant from the corners. A count of individuals by species per subplot was undertaken. Digital photographs were taken of at least every 10th tree and Foliage Projected Cover (FPC) was measured at $1 \mathrm{~m}$ intervals along three $50 \mathrm{~m}$ transect lines using standard procedures (Specht, 1970). For non-forest and regrowth areas located within two SSUs, five $10 \times 10 \mathrm{~m}$ plots rather than one $50 \times 50 \mathrm{~m}$ plot were established because of the high density of small trees occurring. Following field data collection, destructive harvesting of the major tree species (C. glaucophylla; $n=22)$, E. populnea $(n=7)$ and E. melanaphloia $(n=5)$ across the diameter range was undertaken to either generate new allometric equations (in the case of $C$. glaucophylla) for the estimation of AGB from size (e.g., diameter or height) measurements or to evaluate the utility of those already existing (i.e., E. populnea and E. melanaphloia), Burrows et al., 2002). Harvesting was undertaken also such that separate equations could be generated for the estimation of leaf, branch and trunk biomass as well as total AGB (Lucas et al., 2004).

\subsection{Acquisition of LiDAR data}

Commencing on the 24th August 2000 and overlapping with the period of field data collection, LiDAR data (first and last returns) were acquired for each of the PSUs over a one week period using an Optech 1020 scanning system mounted in a Bell Jet Ranger helicopter. Data were acquired at a nominal altitude of $250 \mathrm{~m}$, with a swath width of $\sim 200 \mathrm{~m}$ (centred on each PSU) and a beam divergence of 0.3 milliradians. At this flying height, a footprint of $<15 \mathrm{~cm}$ was obtained giving an average sample interval of $\sim 1 \mathrm{~m}$ along track and between scans. With full differential GPS corrections and an inertial navigation system (INS) that compensated for aircraft pitch, yaw and roll, coordinates with an absolute accuracy of $<1 \mathrm{~m}$ in the $x$ and $y$ directions and $<0.15 \mathrm{~m}$ in elevation were obtained. The data were acquired under dry and clear conditions. During the time of data acquisition, strong westerly winds prevailed but as the helicopter was travelling in an east-west direction, their influence on the spatial integrity of the data was minimized. A GPS base station was established during the LiDAR flights to facilitate accurate georeferencing of the data.

\subsection{Acquisition of NASA JPL AIRSAR (POLSAR) data}

On 3rd September, 2000, the NASA JPL AIRSAR (on board a DC-8) acquired fully polarimetric and multifrequency (POLSAR) C-band $(5.6 \mathrm{~cm}$ or $5.3 \mathrm{GHz}), \mathrm{L}-$ band $(23.9 \mathrm{~cm}$, $1.25 \mathrm{GHz})$ and P-band (68 cm wavelength, $0.44 \mathrm{GHz}$ frequency) band data across the entire PSU grid. The POLSAR data were acquired in four parallel strips (Strip 1-Strip 4; length and width of approximately 80 and $12.5 \mathrm{~km}$, respectively) in a "race track" flight path (Fig. 2) and from an altitude of $\sim 8294 \mathrm{~m}$. An overlap of approximately $1 \mathrm{~km}$ between adjacent POLSAR strips was accommodated in the flight planning. As a large amount of data was acquired, each strip was divided into two during initial processing at JPL resulting in the provision of eight images. During the overflight, 148 of the 150 PSUs were imaged. Taking into account the $1 \mathrm{~km}$ overlap between POLSAR strips, the four images collectively covered an area of $2760 \mathrm{~km}^{2}$. The incidence angle at which the PSUs were observed varied from $26.6^{\circ}$ (near range) $-59.9^{\circ}$ (far range), but no PSUs were located in the incidence angle ranges of $<26.6^{\circ}, 34.9-45.8^{\circ}$ and $50.3-57.4^{\circ}$ (Table 1).

The eight POLSAR images were synthesized from the 16look compressed Stokes Matrix into $\mathrm{HH}, \mathrm{VV}$ and $\mathrm{HV}$ polarizations (as well as total power, TP) to a pixel size in range and azimuth of $4.62 \mathrm{~m}$. These data were slant-to-ground range corrected to a nominal pixel size of $5 \mathrm{~m}$ (Van Zyl et al., 


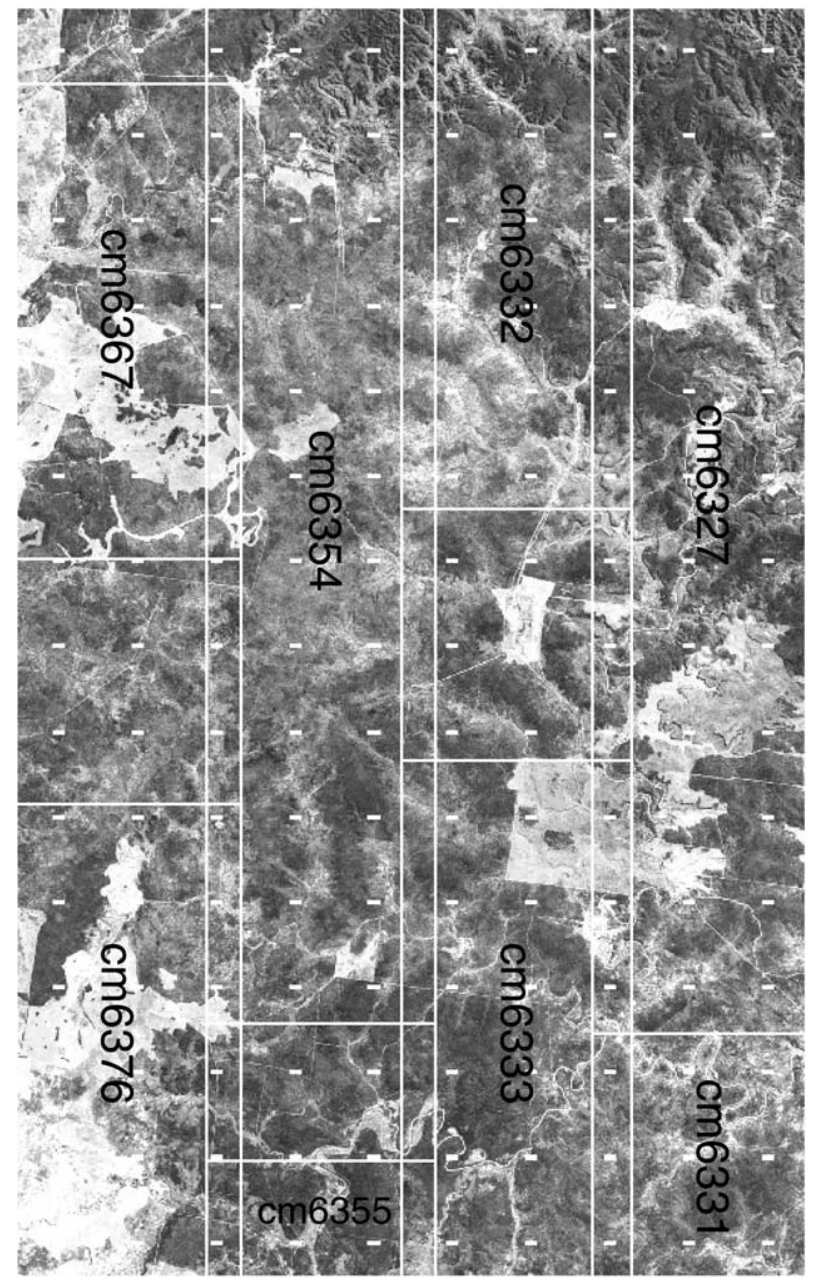

Fig. 2. Location of the AIRSAR flight strips presented against a Landsat Enhanced Thematic Mapper $(\mathrm{ETM}+)$ image of the $37 \times 60 \mathrm{~km}$ Injune study area. The PSU grid is also shown (in white) and the distance between PSU centres is approximately $4 \mathrm{~km}$.

1987; Zebker et al., 1987) and the four strips were recombined. Geometric rectification to Universal Transverse Mercator (UTM) coordinates was then achieved using ground control points (GCPs) established between each of the AIRSAR strips and Landsat ETM+ data of the study area acquired in September, 2000. These data had been georeferenced previously (to a pixel size of $25 \mathrm{~m}$ ) using an independent set of GCPs and procedures standardised within the Queensland Department of Natural Resources (QDNR) Statewide Land Cover and Trees Study (SLATS; SLATS, 2003). Between 100150 GCPs were established for each POLSAR strip, generating
RMS errors of $<10 \mathrm{~m}$ and a third order polynomial nearest neighbour transformation was applied during the registration process. Comparison with fine spatial resolution data (LiDAR, LSP and also CASI data) confirmed high registration accuracy. Following georeferencing, each ground range image was resampled to $10 \mathrm{~m}$ pixel size through pixel averaging. Topographic correction was not applied as the terrain within the $37 \times 60 \mathrm{~km}$ study area was considered to be largely "flat", consisting of valley bottoms, plains or plateaux, or only slightly undulating. As the influence of incidence angle on the retrieval of AGB was a topic of interest, no corrections were undertaken. The POLSAR strips were finally combined to produce a seamless mosaic for the Injune area, a subset of which is presented in Fig. 3.

\section{Data analysis}

\subsection{Estimation of $A G B$ for field plots}

From the oven-dry weights of the harvested trees and using ratio-sampling, new allometric equations relating $D_{30}, D_{130}$ and $H$ to leaf, branch and trunk biomass were generated for $C$. glaucophylla (Burrows et al., 2001). Application of the existing equations of Burrows et al. (2002) to the harvested individuals of $E$. populnea and E. melanaphloia confirmed that these equations were well suited for the estimation of component and total AGB, although divergence in the estimates occurred where the diameter (at $30 \mathrm{~cm}$ ) was $>40 \mathrm{~cm}$. However, for the majority of E. melanaphloia and E. populnea trees measured in the Injune plots, $D_{30}$ was $<40 \mathrm{~cm}$. These equations were considered applicable to most Eucalyptus species in the area as data from Burrows et al. (2000) and a review by Eamus et al. (2001) confirmed the similarity in the gain and offset coefficients for species of the same form within similar environmental envelopes. Equations were not available for $A$. leiocarpa and other large-sized Angophora and Eucalyptus species, largely because of the difficulties associated with their harvesting. For these species, the equation for E. melanaphloia was considered the most appropriate for trees in this forested environment. The component biomass of A. harpophylla and understorey species, including Sandalwood Box (Eremophila mitchellii) and Wilga (Geijera parviflora), was estimated using the equations of Harrington (1979). As recommended by Burrows et al. (2000), a bias correction factor was applied for all species. A summary of equations used is given in Table 2.

For each of the 32 field plots, measurements of size $\left(D_{30}\right.$, $D_{130}$ and $H$ ) were used as input to allometric equations for

Table 1

AIRSAR incidence angles for each of the PSU columns

\begin{tabular}{llllllll}
\hline Strip & Image code & PSU column & Incidence angle range & Strip & Image code & PSU column & Incidence angle range \\
\hline 1(West) & Cm6367/ & 1 & $58.1-59.9$ & 3 & Cm6332/ & $6 \mathrm{~b}$ & $57.8-60.0$ \\
& Cm6376 & 2 & $47.5-50.5$ & & Cm6333 & 7 & $46.0-49.3$ \\
& & 3 & $29.8-34.9$ & & & $8 \mathrm{a}$ & $30.3-33.8$ \\
2 & Cm6354/ & 4 & $26.6-31.0$ & & Cm6327/ & $8 \mathrm{~b}$ & $27.3-32.6$ \\
& Cm6355 & 5 & $45.8-48.3$ & & & 9 & 10 \\
& & $6 \mathrm{a}$ & $57.2-58.8$ & & & $57.4-49.0$ \\
\end{tabular}




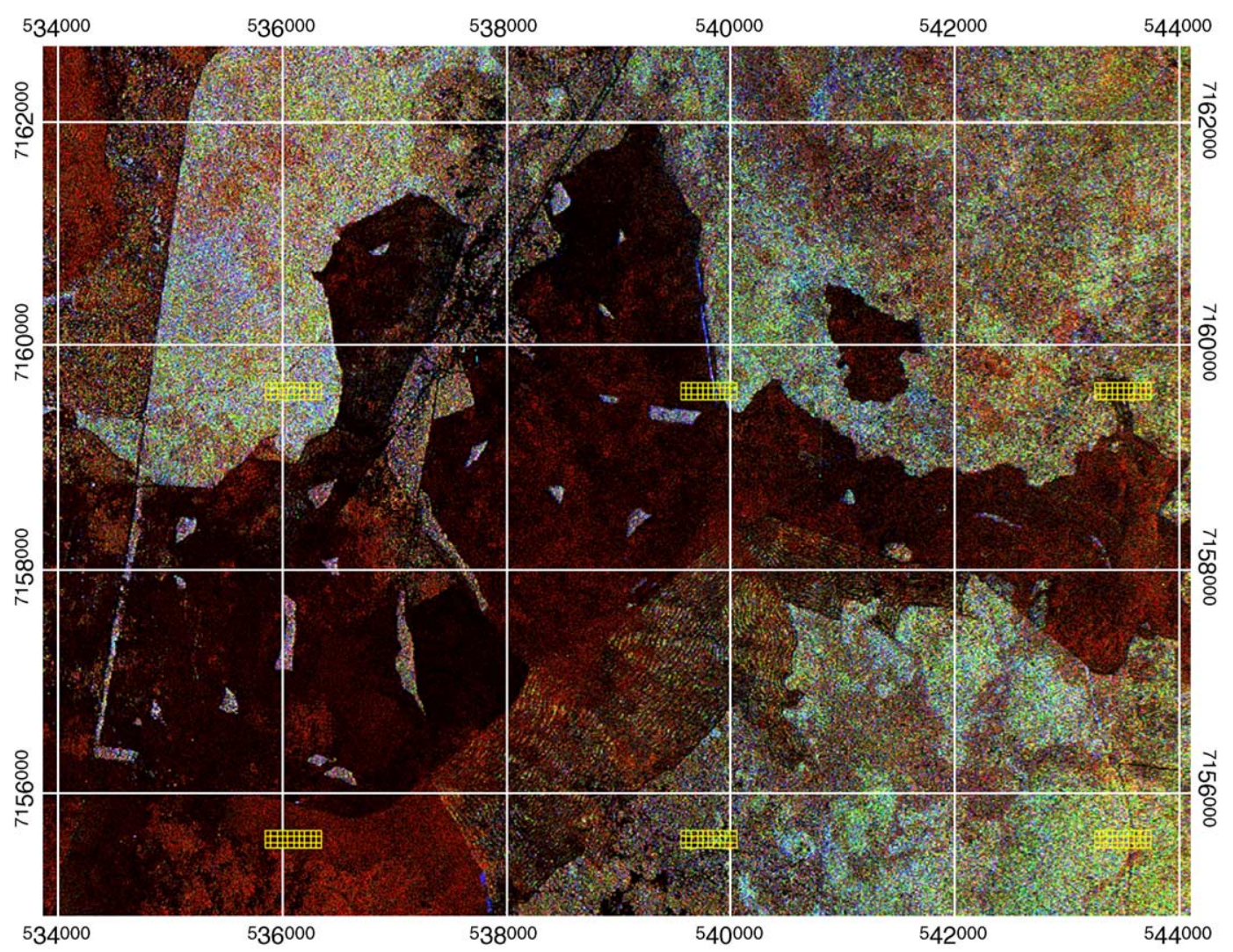

Fig. 3. Subset of the AIRSAR mosaic of the Injune study area (C, L and P-band total power images in RGB) showing the location of PSUs 111 (top left) to 123 (bottom right).

estimating the component biomass of each tree. These estimates were then summed to give total AGB and the estimates for all trees measured were combined subsequently to produce an AGB estimate per 0.25 ha plot, scaled to megagrams per hectare. Comparison of the AGB estimated directly from a single allometric equation for estimating total AGB produced differences in the order of less than $1-2 \mathrm{Mg} \mathrm{ha}^{-1}$.

\subsection{AGB estimation using LiDAR}

The scaling-up field-based estimates of AGB using LiDAR data was based on the premise that measures of tree height, crown dimensions (which relate to cover) and the vertical distribution and density of canopy elements within a unit area needed to be combined to give an overall indication of AGB. The following sections outline the retrieval of this information from the LiDAR data and the formulation of scaling-up procedures.

\subsubsection{Tree height}

Prior to delivery, the LiDAR data were pre-classified into ground and non-ground returns using proprietary software developed for the Optech 1020. Both first and last ground returns were then used to generate an initial elevation surface of $1 \mathrm{~m}^{2}$ pixel size. Visual assessment of the ground surface identified significant fine scale variation, which appeared to relate to returns from surface covers including tall grass and fallen wood debris. To derive a bare earth elevation surface, a multi-scale spatial filtering strategy was developed whereby the lowest returns within local search areas of increasing dimension (i.e., $1 \times 1 \mathrm{~m}, 2 \times 2 \mathrm{~m}, 3 \times 3 \mathrm{~m}$ and $5 \times 5 \mathrm{~m}$ ) were identified. An elevation standard deviation surface was also determined using the data from the $5 \times 5 \mathrm{~m}$ search area. This surface was then used to determine which ground returns were to be used for the final elevation surface. Specifically, where there was low deviation, the lowest returns from the $3 \times 3$ search area were used, whereas where areas supported a high deviation (e.g., those associated with drainage lines or streams), the lowest returns from the $1 \times 1$ or $2 \times 2$ search areas were used. All returns were then intersected with the final ground elevation surface such that a ground elevation value was assigned to each return. The height above ground value for each return was then calculated as the difference between return and ground elevation. Typically, grass swathes can grow up to $0.5 \mathrm{~m}$ in height, and so only returns above this threshold were associated with woody vegetation.

Comparisons between LiDAR and field-measured tree heights, as with most studies worldwide (e.g., Lim et al., 2003; Means et al., 1999), suggested a strong correspondence, with the former considered to be more reliable (Holmgren et al., 2003; Hyyppa et al., 2001). However, for the Injune forests, height alone was generally not considered a consistent indicator of AGB as trees of differing size (measured in terms of trunk diameter) were often of similar height. Specifically, within forests dominated by Callitris species, and of the excurrent (i.e., conifer-like) structural form (Dobson et al., 1995; Lucas et al., 
Table 2

Allometric equations for estimating the biomass of common forest species

\begin{tabular}{|c|c|c|c|c|c|c|c|c|c|c|c|}
\hline Species & Status & $\begin{array}{l}\text { Biomass } \\
\text { component }\end{array}$ & Form of equation & Independ. variable & $a$ & $b$ & $n$ & $r^{2}$ & $\begin{array}{l}\text { Antilog correction } \\
\text { factor }^{\mathrm{a}}\end{array}$ & $\begin{array}{l}\text { Min. size } \\
(\mathrm{cm})\end{array}$ & $\begin{array}{l}\text { Max size } \\
(\mathrm{cm})\end{array}$ \\
\hline \multirow[t]{3}{*}{ Callitris glaucophylla ${ }^{\mathrm{b}}$} & & Leaf & $\ln Y=a+b \ln X$ & $\mathrm{C}(30 \mathrm{~cm})$ & -5.061 & 1.682 & 22 & 0.95 & $\mathrm{n} / \mathrm{a}^{\mathrm{c}}$ & $7.5^{\mathrm{d}}$ & 135 \\
\hline & & Branch & & & -6.582 & 2.305 & 22 & 0.95 & $\mathrm{n} / \mathrm{a}$ & & \\
\hline & & Trunk & & & -6.845 & 2.727 & 22 & 0.99 & $\mathrm{n} / \mathrm{a}$ & & \\
\hline \multirow[t]{3}{*}{ Eucalyptus populnea ${ }^{\mathrm{e}}$} & Intact & Leaf & $\ln Y=a+b \ln X$ & $\mathrm{C}(30 \mathrm{~cm})$ & -3.491 & 1.259 & 22 & 0.81 & 0.659 & $4.6^{\mathrm{d}}$ & 240 \\
\hline & & Branch & & & -5.554 & 2.344 & 22 & 0.92 & 0.713 & & \\
\hline & & Trunk & & & -2.873 & 1.761 & 22 & 0.90 & 0.625 & & \\
\hline \multirow{3}{*}{$\begin{array}{l}\text { Eucalyptus } \\
\quad \text { melanophloia }{ }^{\mathrm{f}}\end{array}$} & Intact & Leaf & $\ln Y=a+b \ln X$ & $\mathrm{C}(30 \mathrm{~cm})$ & -6.227 & 1.851 & 20 & 0.94 & 0.442 & $6.0^{\mathrm{d}}$ & 165 \\
\hline & & Branch & & & -8.300 & 2.913 & 20 & 0.98 & 0.406 & & \\
\hline & & Trunk & & & -7.191 & 2.724 & 20 & 0.98 & 0.354 & & \\
\hline \multirow[t]{2}{*}{ Geijera parviflora $^{\mathrm{g}}$} & & Leaf & $\ln Y=a+b \ln X$ & $\mathrm{C}(30 \mathrm{~cm})$ & -2.156 & 1.614 & 9 & 0.65 & 1.040 & $385^{\mathrm{h}}$ & 702 \\
\hline & & Wood & $\ln Y=a+b \ln X$ & $\mathrm{C}(30 \mathrm{~cm})$ & -2.028 & 2.119 & 9 & 0.86 & 1.220 & & \\
\hline \multirow[t]{2}{*}{ Eremophila mitchelli ${ }^{\mathrm{g}}$} & & Leaf & $\ln Y=a+b \ln X$ & $\mathrm{C}(30 \mathrm{~cm})$ & -4.453 & 2.257 & 18 & 0.90 & 1.150 & $60.0^{\mathrm{h}}$ & 520 \\
\hline & & Wood & $\ln Y=a+b \ln X$ & $\mathrm{C}(30 \mathrm{~cm})$ & -3.890 & 2.623 & 18 & 0.96 & 1.080 & & \\
\hline \multirow[t]{3}{*}{ Acacia harpophylla ${ }^{\mathrm{g}}$} & & Leaf & $\ln Y=a+b \ln X$ & $\mathrm{C}(30 \mathrm{~cm})$ & -2.84 & 1.629 & 29 & 0.60 & $\mathrm{n} / \mathrm{a}$ & $60.0^{\mathrm{h}}$ & 320 \\
\hline & & Branch & & $\mathrm{C}(30 \mathrm{~cm})$ & -4.056 & 2.15 & 29 & 0.69 & $\mathrm{n} / \mathrm{a}$ & & \\
\hline & & Trunk & & $\mathrm{C}(30 \mathrm{~cm})$ & -7.49 & 2.611 & 29 & 0.86 & $\mathrm{n} / \mathrm{a}$ & & \\
\hline
\end{tabular}

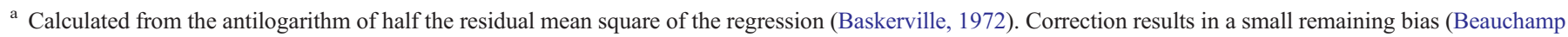

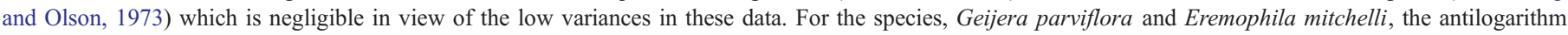

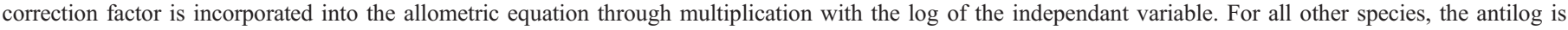
squared, divided by two and added to the $\log$ of the independent variable.

b Destructively harvested from Injune (Latitude-2532', Longitude $147^{\circ} 32^{\prime}$, Burrows et al., 2001).

${ }^{c}$ Not published although calculated in this study using the procedures of Beauchamp and Olson (1973).

${ }^{\mathrm{d}}$ Circumference at $30 \mathrm{~cm}(\mathrm{~cm})$.

e Derived from Dingo, Central Queensland (Latitude - 2339', Longitude 149²4); (Burrows et al., 2000).

${ }^{f}$ Destructively harvested, Central Queensland (Latitude $-23^{\circ} 45^{\prime}$, Longitude $146^{\circ} 02$ ); Burrows (unpublished data).

g Destructively harvested, 'Oakvale', near Coolabah NSW (Latitude 3055', Longitude $146^{\circ} 30$ ); (Harrington, 1979 ).

h Top height $(\mathrm{cm})$.

2004), height was considered to be a reliable indicator of AGB as increases were proportional to diameter in all but the later stages of growth. However, within the forest stands containing trees of the decurrent structural form (i.e., supporting a large expansive branch network), such as Eucalyptus and Angophora species, diameter (and hence AGB) increased with height during the early stages of growth but once a certain height had been attained, increases in diameter with crown area were more evident until the trees reached senescence. In this later stage, a decrease in crown or foliage cover was observed. For this reason, an additional measure relating to crown or foliage cover was considered necessary for LiDAR-based assessment of AGB, particularly where excurrent forms dominated.

\subsubsection{Crown cover}

Crown cover (CC) has been defined as the percentage of an area within the vertical projection of the periphery of crowns, where crowns are considered opaque (McDonald et al., 1998). $\mathrm{CC}$ estimates from the field data (in the range $0 \%$ to $100 \%$ ) were based on the area of crowns when viewed overhead and therefore considered the overlap between crowns at different heights. To generate equivalent CC estimates from LiDAR data, returns greater than $2 \mathrm{~m}$ in height were considered as tree crown elements and were interpolated using the highest returns within a defined search radius (typically 1 or $2 \mathrm{~m}$ ) to produce a top of canopy surface at $1 \mathrm{~m}^{2}$ pixel size. The $2 \mathrm{~m}$ height threshold was used to conform to definitions of forest cover (BRS, 2003), with all $1 \mathrm{~m}$ pixels above this threshold coded as 1 or 0 otherwise. For each field plot, canopy cover percent
$(\mathrm{CC} \%)$ was calculated as the sum of all cells with a value of 1 as a percentage of the total. A comparison of field-based assessments of $\mathrm{CC}$ from all trees with a diameter at breast height $(\mathrm{DBH})>5 \mathrm{~cm}$ with LiDAR-derived estimates produced a good correspondence $\left(r^{2}=0.79, \operatorname{RSE}=9.40, n=32\right)$. Even so, the LiDAR provided a slightly higher estimate of CC compared to the field measurements, largely because a more realistic representation of the irregular shape of crowns was given. By comparison, the field crowns were only measured in the northsouth and east-west directions, and hence only an elliptical area could be calculated.

\subsubsection{Distribution and density of canopy elements}

An indication of the vertical distribution and density of crown elements, which relates to the amount of leaves and branches and hence the biomass of these components, also requires consideration when scaling-up field-based estimates of AGB. In most closed forests, the LiDAR beam reflects largely from the upper surface of the canopy and a lower proportion is typically returned from within the canopy or from the understorey. In many cases, a ground surface return is not recorded. However, within the study area, the forest stands and also the crowns of many individual trees (particularly Angophora and many Eucalyptus species) are more open and returns from within the canopy, the understorey vegetation, and the underlying ground surface are commonplace. For these forests, apparent vertical profiles of LiDAR returns by height are seen as indicative of the depth of the canopy and also the density of canopy elements 


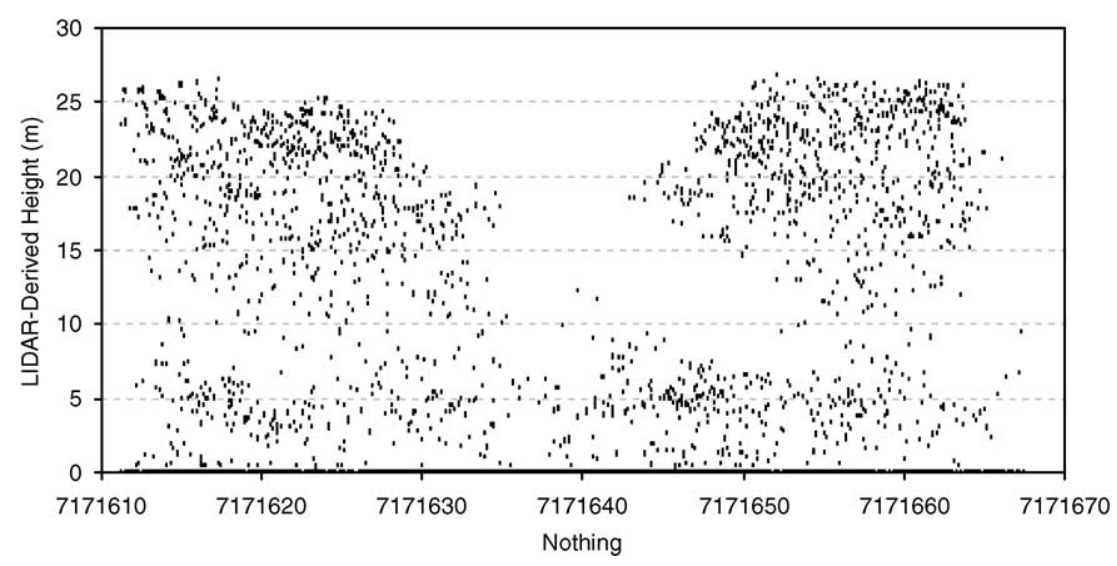

Fig. 4. Profile view of LiDAR (PSU 81-11) showing the distribution of returns by height.

through the vertical profile, as illustrated in Fig. 4. A number of summary heights per SSU were derived from all the vertical strikes within the canopy, which broadly aligns with the canopy-based quartile estimator methods described in Magnussen and Boudewyn (1998) and Lim and Treitz (2004). Canopy heights were calculated by sorting all vegetation heights $(>0.5 \mathrm{~m})$ from the lowest to the highest and calculating the cumulative percentage value of each return in the sorted list (i.e., the lowest and highest returns are given values of $0.1 \%$ and $100 \%$, respectively). Each return was attributed with this additional information, from which the height of vegetation could be determined for a given percentage of all vegetation returns. In the example given in Fig. 4 (SSU 81_11), 50\% of returns are found at $18 \mathrm{~m}$ or higher. As the plot-scale height summary method considers all foliage and branches within the plot rather than individual trees per se, any potential height biases associated with larger crowned trees being sampled by more LiDAR returns were not considered to be problematic as these trees provide correspondingly more biomass to the overall plot estimate.

\subsubsection{AGB estimation from $L i D A R$ parameters}

To integrate the information on vegetation height, $\mathrm{CC}$ and the vertical distribution and density of returns, both forward and backward stepwise linear regressions were evaluated for 32 plots. Initially, 20 "potential" vegetation height classes (based on $5 \%$ intervals of the cumulative percentage values) were tested. From this set, six height variables and CC were found to be the most significant for estimating AGB. Using six vegetation height classes was also considered a compromise between having a simple and robust model that was parsimonious with the number of explanatory variables versus having sufficient variables to describe the variability in height within and between strata. The LiDAR-derived AGB $\left(\mathrm{Mg} \mathrm{ha}^{-1}\right)$ was therefore described by Eq. (1):

$$
\begin{aligned}
\mathrm{AGB}= & \left(\beta_{1} \chi_{h 5}\right)+\left(\beta_{2} \chi_{h 10}\right)+\left(\beta_{3} \chi_{h 20}\right)+\left(\beta_{4} \chi_{h 40}\right) \\
& +\left(\beta_{5} \chi_{h 75}\right)+\left(\beta_{6} \chi_{h 85}\right)+\left(\beta_{7} \chi_{\mathrm{CC}}\right)-I
\end{aligned}
$$

where $\beta_{n}$ represents the regression coefficient; $\chi_{n}$, the LiDAR parameters outlined in Table $3 ; h$, the height of vegetation at $n$ (\%) of the LiDAR returns; CC, the LiDAR interpolated Crown
Cover (\%); and $I$, the intercept. The regression coefficients are also presented in Table 3. Foliage Projected Cover (FPC) derived from LiDAR data calibrated with field data was tested in place of LiDAR-interpolated CC but was found to be a less useful predictor.

To obtain the best possible prediction error estimates, all field plots were used in the model calibration. Given the small number of field plot estimates of AGB, splitting the data into fit and validation sets would result in little gain in reliability (Roecker, 1991 in Jerez et al., 2005). The reliability of the LiDAR biomass model was therefore assessed as follows. First, AGB estimates for the forests within the study area were calculated by applying independent biomass scale factors of Barrett et al. (2001) and Burrows et al. (2002) to existing mapped vegetation data. Whilst scale and sampling issues are associated with using different data sources, the AGB calculated was $-11 \%$ and $13 \%$, respectively compared to those generated using the LiDAR. Second, the distribution of AGB calculated for all 4500 SSUs corresponded with that of the field-based estimates and no values occurred outside of the expected range. The use of Eq. (1) for estimating AGB was therefore considered sufficiently robust across the observed range of $\mathrm{AGB}\left(r^{2}=0.92, \mathrm{SE}=12.06 \mathrm{Mg} \mathrm{ha}^{-1}, n=32\right.$; Fig. 5), including for forests above $100 \mathrm{Mg} \mathrm{ha}^{-1}$, and structures occurring within the study area. Following formulation, fully automated procedures were applied across all 150 PSUs to estimate AGB for each of the 4500 SSUs. An example of the AGB estimates for the SSUs within PSU 81 is given in Fig. 6.

Table 3

Regression parameters and coefficients used for Eq. (2)

\begin{tabular}{llcl}
\hline $\begin{array}{l}\text { Parameter } \\
\text { number }\end{array}$ & $\begin{array}{l}\text { Regression } \\
\text { parameter }\end{array}$ & $\begin{array}{l}\text { Regression } \\
\text { coefficients }\end{array}$ & Strata \\
\hline 1 & $l^{l} \chi_{h 5}$ & -47.1 & Understorey \\
2 & $\chi_{h 10}$ & 60.8 & Understorey \\
3 & $\chi_{h 20}$ & -20.7 & Understorey \\
4 & $\chi_{h 40}$ & 3.6 & Overstorey \\
5 & $\chi_{h 75}$ & -5.5 & Overstorey \\
6 & $\chi_{h 85}$ & 7.4 & Overstorey \\
7 & $\chi_{C C}$ & 0.9 & Both \\
8 & $I$ & -23.2 & \\
\hline
\end{tabular}

${ }^{l} \chi_{h 5}$, for example, represents height at $5 \%$ of the LiDAR returns from the cumulative height curve. 


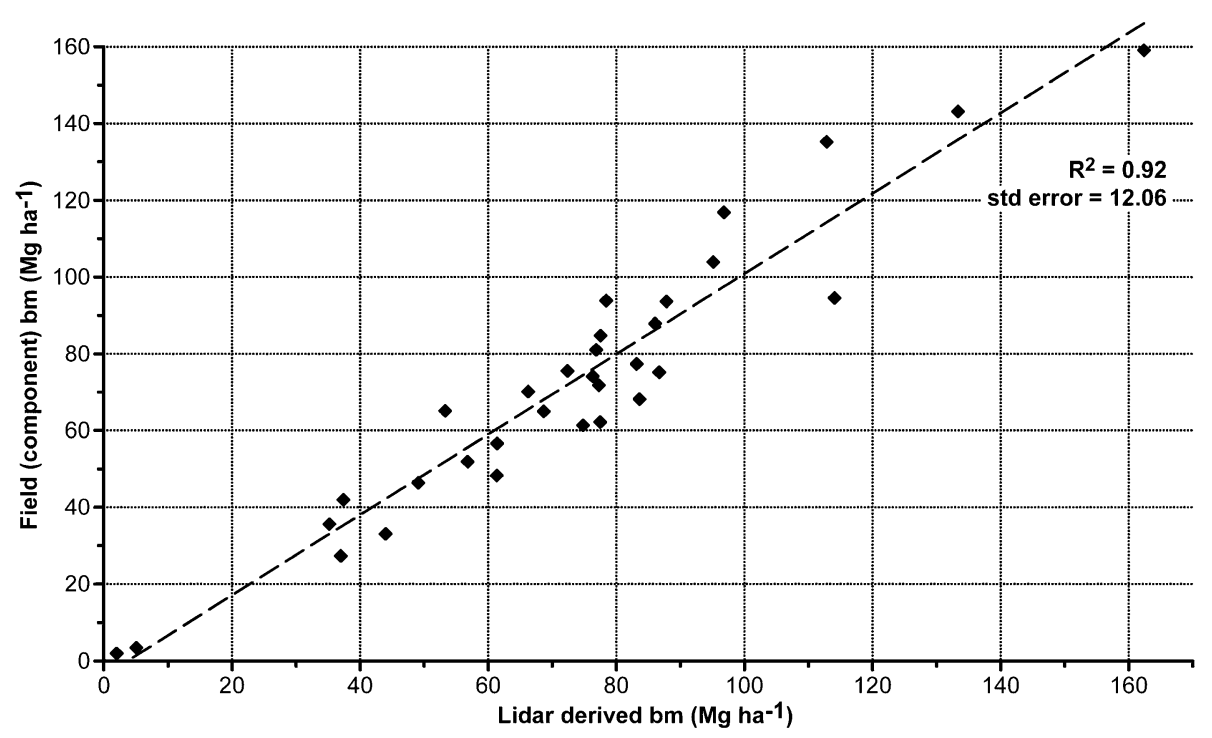

Fig. 5. Comparison between field-derived estimates and those generated using a stepwise linear regression between field (leaf + branch + trunk) and LiDAR (heights $+\mathrm{CC}$ above $2 \mathrm{~m}$ ).

\subsection{Extraction of AIRSAR data}

To establish relationships between the LiDAR-derived AGB and SAR backscatter at different frequencies, polarizations and incidence angles, AIRSAR C-, L- and P-band backscatter data were extracted independently from each of the 10 PSU columns. PSU columns C3 and C8 were each observed within two adjacent and overlapping AIRSAR strips. As the incidence angle was similar in the overlap regions, data for $\mathrm{C} 3$ were extracted from Strip 1 (NASA JPL Flight reference cm6367/ 6376) rather than Strip 2 whilst data for C8 were extracted from Strip 3 (cm6332/6333; C8) rather than Strip 4. The data from C8 to 10 (Strip 4; cm6327/6331) were later excluded however because of data anomalies in P-band. For some columns, nonforested surfaces did not occur within the contained SSUs. Therefore, backscatter data were extracted from additional "pseudo SSUs" identified as being non-forest from available optical (e.g., Landsat sensor) imagery and located north and/or south of the existing PSUs. Through this approach, the data were extracted from the same incidence angle at which the PSU column was observed. Following extraction, the mean intensity data (25 values per SSU) were converted to the backscattering coefficient $\left(\sigma^{\circ}, \mathrm{m}^{2} \mathrm{~m}^{-2}\right)$ using Eq. (2):

$\sigma^{\circ}\left(d_{\mathrm{B}}\right)=10 \times \log _{10}\left(\sigma^{\circ}\right)$

where $\sigma^{\circ}$ is defined as the average radar cross-section per unit area of the individual scattering elements.

\section{Results}

\subsection{Relationships between SAR backscatter and AGB}

For all PSU columns and for all SAR channels, an increase in SAR backscatter with LiDAR-derived AGB was observed

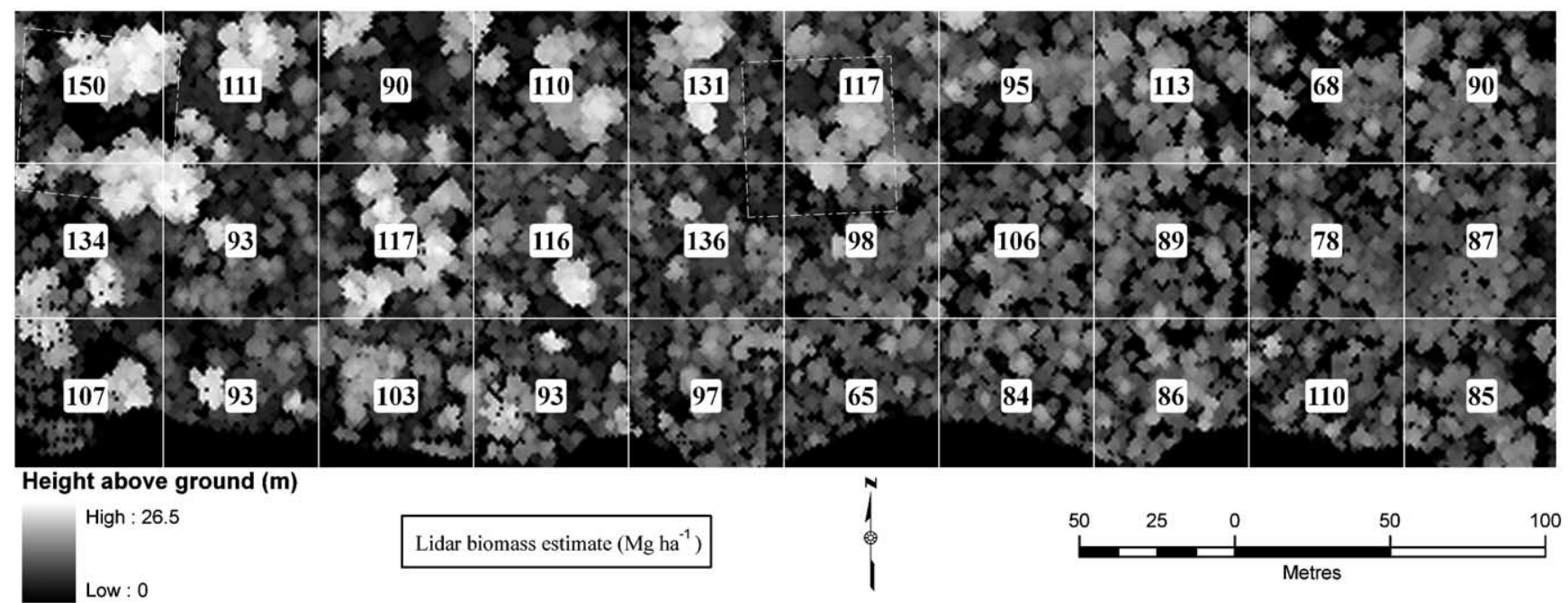

Fig. 6. Tree canopy height raster and predictions of total AGB (generated using Eq. (2) and in white boxes) for each of the 300.25 ha $(50 \times 50 \mathrm{~m}) \mathrm{SSUs}$ within PSU 81. 
up to a level of saturation, which varied with frequency and polarization. To describe this relationship, a number of approaches to fitting a non-linear curve, including the use of logarithmic and polynomial functions (e.g., dos Santos et al., 2003; Rignot et al., 1994), were considered. However, these were found inappropriate for quantifying the relationship, particularly as they failed to adequately describe the increase in SAR backscatter with AGB up to the level of saturation. For this reason, a non-linear equation was used such that:

$\sigma^{\circ}=\beta_{\mathrm{s}}+\left(\left(\beta_{\mathrm{n}}-\beta_{\mathrm{s}}\right) \cdot \exp \left(-k \cdot \beta_{\mathrm{M}}\right)\right)$

where $\sigma^{\circ}$ refers to the backscattering coefficient $\left(d_{\mathrm{B}}\right), \beta_{\mathrm{s}}$ and $\beta_{\mathrm{n}}$ represent the SAR backscatter from a forested and nonforested surface, respectively, $k$ represents a coefficient that describes the gradient of the curve as it tends towards an asymptote and $\beta_{\mathrm{M}}$ represents above ground biomass $(\mathrm{Mg}$ $\mathrm{ha}^{-1}$ ), as derived from LiDAR data. The fitting procedure, which was undertaken within OriginPro software, aimed to identify values of $\beta_{\mathrm{s}}$ and $k$ such that the sum of the squares of the deviations of the theoretical curve (Eq. (3)) from the actual independent data points, as indicated through the chisquare statistic, was at its minimum. When fitting the equation, the mean SAR backscatter value associated with non-forest areas $\left(\beta_{\mathrm{n}}\right)$ was fixed and calculated for each channel as the mean backscatter data for non-forest areas within each PSU column (See Table 6). Values of $k$ varied from 0.021 to 0.043 . The resulting line of best fit was superimposed subsequently over the scatterplot relating actual SAR backscatter and AGB, an example of which is given in Fig. 7. For each point, information relating to the corresponding community composition was also available. The line of best fit, which was considered to well represent the relationship, was applied subsequently to the SAR backscatter data extracted for all channels and from all PSU columns (Fig. 8). From the resulting regression lines, the importance of frequency, polarization and incidence angle on the level of saturation in the relationship between SAR backscatter and $\mathrm{AGB}$ and the overall dynamic range of the data was evaluated.
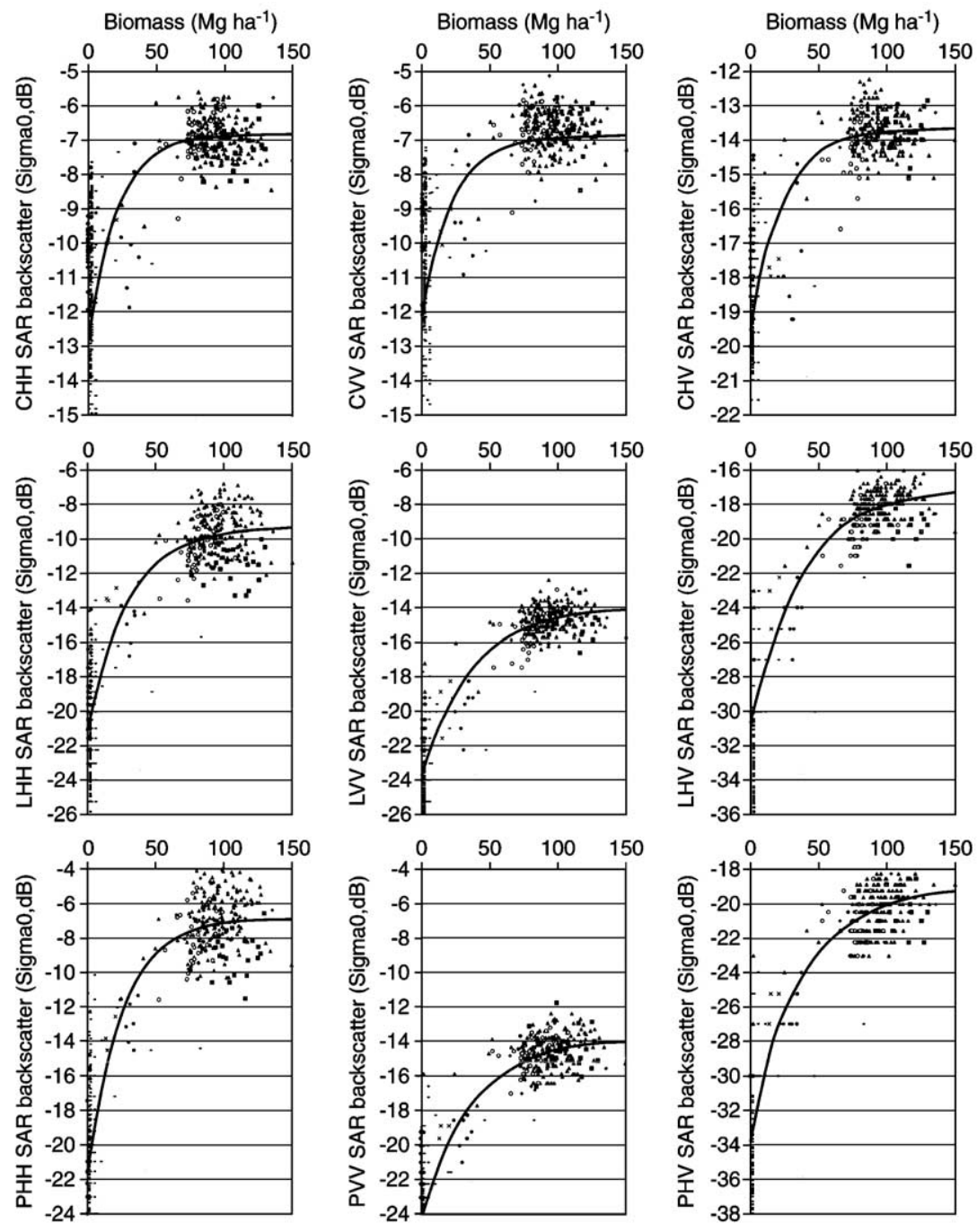

Fig. 7. The relationship between SAR backscatter and the LiDAR-derived AGB as determined for PSU C1 (incidence angle range $58.1-59.9^{\circ}$ ). 

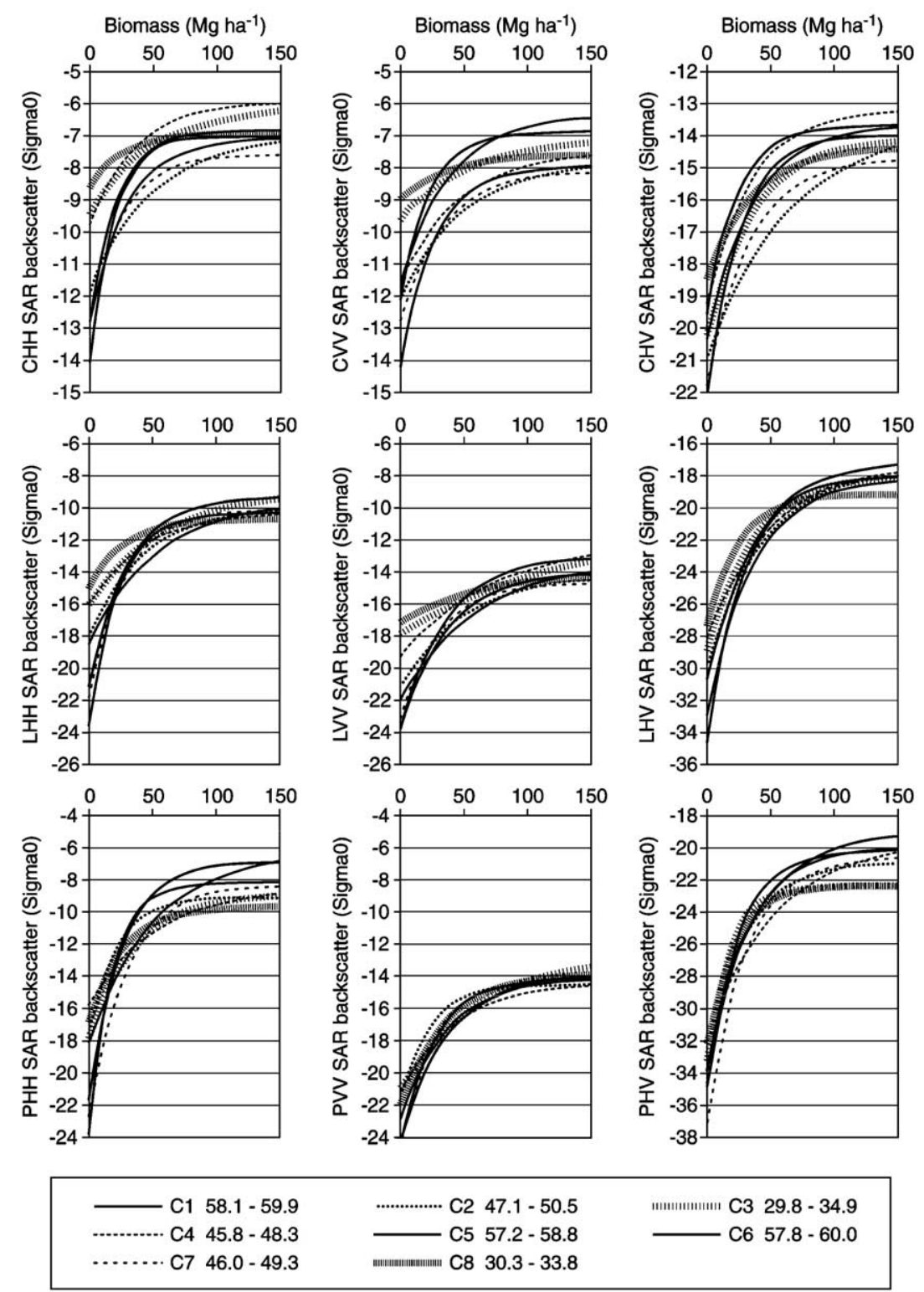

Fig. 8. Non-linear equations describing the relationship between SAR backscatter and biomass for PSU columns $1-8$. The incidence angle at which each PSU column was observed is indicated.

\subsection{Saturation}

The AGB at which the SAR backscatter at different frequencies and polarizations saturated was arbitrarily determined by identifying where the rate of change in the line of best fit was less than $0.2 \mathrm{~dB}$ per $5 \mathrm{Mg} \mathrm{ha}^{-1}$ AGB increase. The AGB at which the backscatter saturated was variable between channels and the different PSU columns, although generally increased at lower frequencies (Table 4). The general trends were highlighted by taking the average, minimum and maximum AGB at which the backscatter saturated for each channel and PSU column (Table 5). For C-band co-polarized data, and not considering incidence angle, saturation occurred at an average of $34 \mathrm{Mg} \mathrm{ha}{ }^{-1}$ (Maximum $=\sim 45-50 \mathrm{Mg} \mathrm{ha}^{-1}$ ) whilst C-band HV backscatter saturated at an average of $53 \mathrm{Mg} \mathrm{ha}^{-1}$ (Maximum $65 \mathrm{Mg}$ $\mathrm{ha}^{-1}$ ). These saturation levels at C-band HV were typically higher than the $20-30 \mathrm{Mg} \mathrm{ha}^{-1}$ typically observed at C-band for closed forests (e.g., Dobson et al., 1992; Imhoff, 1995b; Le Toan et al., 2004), suggesting that this channel could be used for estimating AGB in this more open forest environment. At L-band, saturation was generally lower $(\sim 58-61$ $\mathrm{Mg} \mathrm{ha}^{-1}$; maximum of $75-80 \mathrm{Mg} \mathrm{ha}^{-1}$ ) for the co-polarized data but greater at HV polarization (average of $78 \mathrm{Mg} \mathrm{ha}^{-1}$; maximum of $90 \mathrm{Mg} \mathrm{ha}^{-1}$ ), which again was higher compared to studies of closed forests $\left(\sim 50-60 \mathrm{Mg} \mathrm{ha}^{-1}\right.$; Le Toan et al., 2004; Luckman et al., 1997). At P-band, the average biomass at which saturation was observed ranged from 62 to $72 \mathrm{Mg} \mathrm{ha}^{-1}$ for all polarizations with the highest saturation level of $95 \mathrm{Mg} \mathrm{ha}^{-1}$ observed for the HV polarization. This level was similar to some studies (e.g., dos Santos et al., 2003) although higher levels have been reported in others 
Table 4

Observed levels of saturation in the relationship between SAR backscatter and biomass

\begin{tabular}{|c|c|c|c|c|c|c|c|c|}
\hline Column & $\mathrm{C} 1$ & $\mathrm{C} 2$ & $\mathrm{C} 3$ & $\mathrm{C} 4$ & $\mathrm{C} 5$ & C6 & $\mathrm{C} 7$ & $\mathrm{C} 8$ \\
\hline$\theta^{\circ}$ & $58.1-59.9$ & $47.5-50.5$ & $29.8-34.9$ & $29.6-31.0$ & $45.8-48.3$ & $57.2-58.8$ & $46.0-49.3$ & $30.3-33.8$ \\
\hline $\mathrm{C} \mathrm{HH}$ & 25 & 45 & 25 & 35 & 45 & 45 & 45 & 10 \\
\hline C VV & 40 & 40 & 10 & 40 & 45 & 50 & 40 & 10 \\
\hline $\mathrm{C} \mathrm{HV}$ & 45 & 65 & 55 & 50 & 55 & 55 & 55 & 40 \\
\hline L HH & 65 & 65 & 65 & 55 & 60 & 75 & 65 & 35 \\
\hline L VV & 70 & 65 & 35 & 65 & 75 & 80 & 60 & 20 \\
\hline L HV & 85 & 90 & 70 & 85 & 75 & 85 & 80 & 55 \\
\hline P HH & 70 & 50 & 65 & 65 & 55 & 90 & 75 & 50 \\
\hline P VV & 70 & 45 & 75 & 60 & 60 & 65 & 60 & 60 \\
\hline P HV & 85 & 70 & 50 & 95 & 65 & 75 & 80 & 55 \\
\hline
\end{tabular}

The PSU columns and incidence angles $\left(^{\circ}\right)$ are indicated.

(e.g., Imhoff, 1995a,b; Le Toan et al., 2004). Future observations might consider investigating relationships over similarly structured but higher biomass forests to establish whether higher level of saturation might occur. In all cases, saturation levels varied as a function of incidence angle, as outlined in the next section.

\subsection{Incidence angle dependencies}

For most frequencies and polarizations, but particularly at $\mathrm{HH}$ and $\mathrm{HV}$ polarizations, the higher levels of AGB at which saturation was observed were generally associated with data acquired at larger $\left(>\sim 45^{\circ}\right)$ incidence angles (Tables 4 and 5). At incidence angles of 57.2-59.9 , L-band and P-band saturation levels were consistently greater than $65-70 \mathrm{Mg}$ $\mathrm{ha}^{-1}$. Differences between incidence angles were less evident at C-band, although saturation levels tended to be slightly greater at incidence angles exceeding $\sim 45^{\circ}$.

Variability in average SAR backscatter for non-forest as a function of both channel and incidence angle were also observed (Table 6) and was considered to be a greater influence on the dynamic range of the data than the variability associated with forests at the level of saturation. At C-band, for example, the backscattering coefficient from non-forest noticeably increased at lower incidence angles but the backscattering coefficient from forest (at the level of saturation) was comparatively stable. The variability in the backscattering coefficient from the ground surface with differences in incidence angle was less noticeable at lower frequencies. At these lower frequencies, the roughness scale of the surface is a smaller fraction of the wavelength, and the surface appears smoother to the incidence waves. Most of the incident energy is scattered forward, and the backscattering cross-section is very small with weak variations with incidence angle (except at very small angles). For higher frequencies, where the surface appears much rougher to the incident wave, the significant part of incident energy is still scattered forward, but scattering in all other directions also becomes higher. Therefore, the backscattering dependence on the incidence angle is more pronounced for the higher frequencies and the backscattering coefficient is also higher at lower incidence angles.

To illustrate the importance of incidence angle on the potential to retrieve $\mathrm{AGB}$, the backscatter dynamic range $(\alpha)$ for each frequency and polarization and for each PSU column was calculated using:

$\alpha_{i}=\sigma^{\circ} s_{i}-\sigma^{\circ} g_{i}$

where, for channel $i, \sigma^{\circ} s$ represents the backscattering coefficient at the saturation level and $\sigma^{\circ} g$ the mean SAR backscattering coefficient for non-forest areas. A similar approach based on the ratios of backscattering coefficient for the two surfaces was adopted by Le Toan et al. (1992) This analysis indicated that $\mathrm{C}$-band $\mathrm{HH}$ and $\mathrm{VV}$ backscattering coefficient from non-forest areas was lower at high (57.2$\left.59.9^{\circ}\right)$ compared to low $\left(29.8-34.0^{\circ}\right)$ incidence angles (Table 7). At the higher incidence angles also, the dynamic range at $\mathrm{C}$ band $\mathrm{HH}$ and $\mathrm{VV}$ was greater whilst that at C-band $\mathrm{HV}$ was more similar at all recorded incidence angles. At L-band, the co-polarized backscatter was similarly lower from non-forested areas at high incidence angles and increased with decreasing incidence angle. At higher incidence angles, the dynamic range at L-band $\mathrm{HH}$ and $\mathrm{VV}$ was greater suggesting a higher sensitivity to $\mathrm{AGB}$, although the range at L-band $\mathrm{VV}$ was noticeably reduced relative to L-band $\mathrm{HH}$. L-band $\mathrm{HV}$ de-

Table 5

Average and maximum biomass $\left(\mathrm{Mg} \mathrm{ha}^{-1}\right)$ at which the SAR backscatter saturates

\begin{tabular}{|c|c|c|c|c|c|c|c|c|c|c|}
\hline & Incidence angle range & $\mathrm{C} \mathrm{HH}$ & C VV & C HV & L HH & L VV & L HV & P HH & $\mathrm{P}$ VV & P HV \\
\hline Average & $29.6-34.9$ & 34 & 34 & 53 & 61 & 59 & 78 & 65 & 62 & 72 \\
\hline Average & $29.6-33.8$ & 23 & 20 & 48 & 52 & 40 & 70 & 60 & 65 & 67 \\
\hline Average & $45.8-50.5$ & 45 & 42 & 58 & 63 & 67 & 82 & 60 & 55 & 72 \\
\hline Average & $45.8-59.9$ & 41 & 43 & 55 & 66 & 70 & 83 & 68 & 60 & 75 \\
\hline Average & $29.6-59.9$ & 34 & 34 & 53 & 61 & 58 & 78 & 65 & 62 & 72 \\
\hline Min & $29.6-59.9$ & 10 & 10 & 40 & 35 & 20 & 55 & 50 & 45 & 50 \\
\hline
\end{tabular}


Table 6

Average SAR backscatter for non-forested areas

\begin{tabular}{|c|c|c|c|c|c|c|c|c|c|}
\hline & C1 $58.1-59.9$ & C2 $47.5-50.5$ & C3 29.8-34.9 & C4 29.6-31.0 & C5 $45.8-48.3$ & C6 57.2-58.8 & C7 $46.0-49.3$ & C8 $30.3-33.8$ & Average \\
\hline $\mathrm{C} \mathrm{HH}$ & -13.1 & -11.8 & -9.5 & -9.8 & -14.2 & -12.8 & -12.9 & -8.6 & -11.6 \\
\hline $\mathrm{C}$ VV & -12.3 & -12.1 & -9.6 & -11.7 & -14.2 & -11.7 & -12.8 & -9.0 & -11.7 \\
\hline $\mathrm{C} \mathrm{HV}$ & -19.8 & -21.1 & -20.4 & -19.3 & -22.2 & -20.4 & -21.8 & -18.6 & -20.5 \\
\hline L VV & -23.9 & -21.3 & -17.9 & -19.3 & -23.9 & -22.1 & -23.2 & -17.3 & -21.1 \\
\hline L HV & -30.9 & -29.9 & -29.3 & -28.1 & -34.7 & -32.9 & -33.0 & -27.6 & -30.8 \\
\hline P HH & -22.2 & -18.1 & -18.2 & -15.8 & -24.1 & -18.2 & -22.9 & -17.3 & -19.6 \\
\hline
\end{tabular}

monstrated greater sensitivity to AGB at high and, to a lesser extent, medium incidence angles and the dynamic range was greater compared to both sets of co-polarized data. At P-band, the backscatter for non-forest areas and the dynamic range of the data were relatively similar for non-forest areas regardless of incidence angle, with the exception of P-band $\mathrm{HH}$ where the dynamic range was generally reduced at the lower incidence angles. P-band VV exhibited the lowest dynamic range, regardless of incidence angle.

Scatter in the relationships between SAR backscatter in all channels was generally reduced at large incidence angles (e.g., $\left.58.1-59 \cdot 3^{\circ}\right)$. At lower incidence angles, the greater scatter was attributed, in part, to the reduced dynamic range of the data. Scatter in the relationships were also attributed to variations in the species composition and growth stage of the forests and hence their structure. On the basis of the relationships observed, opportunities for discrimination of forest communities appeared limited using these data alone. The difficulty in discriminating communities using SAR is attributable largely to the complex mix of species and structures that occur throughout the forested areas, particularly as most species occur in association and exist at various stages of regeneration and/or degradation.

\section{Discussion}

\subsection{LiDAR estimates of $A G B$}

The majority of studies (e.g., Dobson et al., 1992; Imhoff, 1995b; Le Toan et al., 2004; Luckman et al., 1997) that have investigated the use of SAR for retrieving the AGB of forests have necessarily relied upon field-based observations for calibration and validation of models. This study instead used field-based observations to develop a regression relationship with fine spatial resolution LiDAR data that was used subsequently for extrapolation across the PSU landscape sampling grid. Through this approach, the AGB of over 4500 $50 \times 50 \mathrm{~m}$ plots (SSUs) covering a range of forest communities and structural types could be estimated. Furthermore, the relative importance of SAR parameters, namely frequency, polarization and incidence angle, could be evaluated.

In the complex, mixed species forests occurring at Injune, the use of both field and LiDAR data for retrieving and extrapolating biomass had limitations. As examples, the fieldbased estimates of AGB were less reliable where larger Angophora trees occur because of the lack of species-specific allometric equations for these species. Some species (e.g., Narrow Leaved Ironbark or E. crebra) were not present in the field plots and so the regression model may not have encompassed the variability in LiDAR returns from all structural types as a function of AGB. Even so, the estimates of AGB for all the SSUs were within the range $\left(<\sim 160 \mathrm{Mg} \mathrm{ha}^{-1}\right)$ expected for this forest environment. Specific instances where the regression did not seem to hold were identified in less than $1 \%$ of all SSUs, and were typically associated with SSUs where large isolated trees with no understorey or where crowns overhanging cliff edges occurred.

\subsection{Empirical relationships with SAR data}

In many PSU columns, there was a relative lack of forests within the lower AGB classes and hence the relationships established with SAR data were influenced more by those in the higher range. The absence of low biomass forests was

Table 7

The difference in SAR backscatter between non-forested and forested areas (i.e., the dynamic range, $\alpha$ ) as a function of incidence angle, frequency and polarisation

\begin{tabular}{|c|c|c|c|c|c|c|c|c|c|}
\hline & C1 58.1-59.9 & C2 $47.5-50.5$ & C3 29.8-34.9 & C4 29.6-31.0 & C5 $45.8-48.3$ & C6 57.2-58.8 & C7 $46.0-49.3$ & C8 $30.3-33.8$ & Average \\
\hline$\alpha_{\mathrm{CHH}}$ & 5.8 & 2.8 & 1.3 & 2.4 & 6.5 & 4.5 & 4.3 & 0.5 & 3.5 \\
\hline$\alpha_{\mathrm{CVV}}$ & 5.2 & 2.5 & 0.4 & 2.5 & 5.1 & 4.0 & 3.3 & 0.3 & 2.9 \\
\hline$\alpha_{\mathrm{CHV}}$ & 5.2 & 4.8 & 4.9 & 4.8 & 7.3 & 5.3 & 5.7 & 2.9 & 5.1 \\
\hline$\alpha_{\mathrm{LVV}}$ & 8.4 & 5.3 & 1.6 & 4.3 & 9.6 & 6.5 & 6.6 & 1.0 & 5.4 \\
\hline$\alpha_{\mathrm{LHV}}$ & 12.4 & 10.7 & 9.9 & 8.9 & 15.5 & 13.3 & 13.8 & 7.5 & 11.5 \\
\hline$\alpha_{\mathrm{PHH}}$ & 14.4 & 8.2 & 7.8 & 5.2 & 15.2 & 9.9 & 13.5 & 6.4 & 10.1 \\
\hline
\end{tabular}


attributable largely to the extensive clearing in the region that accelerated from the early 1990s. Vegetation supporting a lower AGB was often preferentially cleared and maintenance of clearings prevented significant regeneration of forests. Within the agricultural areas also, many large individual trees of high biomass (e.g., Angophora species) were retained to provide cover for stock. Hence the AGB for more open forest areas remained high compared to situations where these trees are removed and regeneration only occurred. AGB was also generally high across the landscape as a high proportion of forest is contained within State Forest areas. A number of options for fitting the regression equations were considered, including the use of logarithmic and higher order polynomial equations (Dobson et al., 1992; dos Santos et al., 2003; Imhoff, 1995a), but the non-linear equation used in this study to fit the data was considered more robust and consistent.

The increase in SAR backscatter with biomass is attributable primarily to greater amounts of scattering elements within forests of higher biomass. In our previous studies (Liang et al., 2005; Lucas et al., 2004) of forests at Injune, the interaction of microwaves of different frequency and polarisation with different components of the forest has been demonstrated with, for example, C-band microwaves of $\mathrm{HV}$ polarisation interacting largely with leaves and small branches and L-band and Pband $\mathrm{HV}$ and $\mathrm{HH}$ with the larger branches and trunks, respectively. At VV polarisations, greater returns from the ground surface were evident. This knowledge was obtained by parameterizing wave scattering models and observing the relationships between component biomass and the backscatter contributions from the different scattering mechanisms to the total. The reader is therefore referred to these papers for a greater insight into the scattering behaviour of these forests.

Obtaining such knowledge from empirical relationships with SAR backscatter is complicated by the inherent relationships between biomass components, as highlighted by Lucas et al. (2000). For example, a true relationship between L-band $\mathrm{HH}$ backscatter and trunk biomass does exist because of microwave interaction with this component. However, because trunk and branch biomass (which together represent the majority of the biomass) are often proportional, a close relationship between L-band $\mathrm{HH}$ backscatter and branch and also total biomass is also observed. These relationships cannot therefore be disaggregated using empirical relationships and hence wave scattering models need to be used. The retrieval of biomass (both total and component) from SAR backscatter is likely to be most reliable in relatively homogeneous forests of similar form where the allocation of biomass to different components is relatively consistent within and between growth stages (Lucas et al., 2004). In the mixed species forests near Injune, retrieval is complicated by the diversity of growth stages and species (and hence structural forms) and this is indicated by the scatter observed in the relationships. These factors should therefore be considered when interpreting the relationships between SAR backscatter and biomass.

As reported by many studies worldwide (Kasischke et al., 1997; Le Toan et al., 2004), an increase in SAR backscatter with AGB to a level of saturation was observed in all channels and was relatively consistent despite the wide range of forest types observed. A noticeable exception, however, was that the saturation level of C-band HV backscatter (at $\sim 50 \mathrm{Mg}$ $\mathrm{ha}^{-1}$ ) was greater and the rate of increase to the level of saturation lower compared to that observed typically for the more closed forests and plantations of the temperate, boreal and tropical regions. In these latter forests, C-band saturation typically occurs at about $20-30 \mathrm{Mg} \mathrm{ha}^{-1}$ and a rapid increase to the saturation level is observed (Dobson et al., 1992; Hoekman \& Quiñones, 2000; Imhoff, 1995b; Le Toan et al., 2004; Moghaddam et al., 1994; Ranson \& Sun, 1994; Rauste et al., 1994). This behaviour is attributable largely to the rapid formation of a closed canopy (Le Toan et al., 1992; Lucas et al., 2000), which leads to attenuation and depolarization of the backscatter through volume scattering from the leaves and small branches (Fig. 9a; Dobson et al., 1992; Liang et al., 2005). However, in more open forests and woodlands (Fig. 9b), such as those within the study area, depolarization by the canopy still occurs but appears to do so in proportion to the closure of the canopy which, in the case of regrowth, is relatively slow and often incomplete. In the early stages of regeneration, the increase in AGB is achieved primarily through increases in tree height and, in most stands, the canopy remains relatively open. Only when a certain height has been attained does the AGB increase more with crown area and hence canopy cover. As crowns start to expand and overlap, C-band backscatter correspondingly increases but saturation only occurs upon formation of a relatively closed canopy (typically no more than $30-70 \%$ in this environment; Dowling \& Accad, 2003). The same effect can occur when trees are removed from the forest (Fig. 9c) as the loss of canopy cover is also in proportion to decreases in AGB, particularly if the more mature individuals are subject to clearance, as is typical in thinning operations (e.g., ring barking or tree poisoning; Fairfax \& Fensham, 2000). These conclusions are supported by strong relationships between C-band HV backscatter and Foliage Projected Cover (FPC), which suggest saturation at a level of approximately $50 \%$ FPC, and a close correspondence between FPC and both basal area and AGB (Cronin et al., 2005; Specht \& Specht, 1999). Modelling studies of these forests (Lucas et al., 2004) also confirm preferential and near exclusive interaction of Cband HV backscatter with leaves and small branches. As changes in FPC are also in proportion to changes in woody AGB in most stands, whether regenerating for subject to thinning or other forms of removal, the level of saturation and the rate of SAR backscatter change with AGB at C-band HV suggest that this channel can be used for retrieval, albeit to a lower level, where L and P-band data are not available.

\subsection{Influence of incidence angle}

Using airborne SAR, AGB retrieval or classification of forests is complicated because of variation in the incidence angle across the scene and such difficulties are often overcome by confining analysis to a small incidence angle range (Le Toan et al., 1992; Rignot et al., 1994). Using spaceborne SAR, the incidence angle is fixed and there is minimal variation across 
a

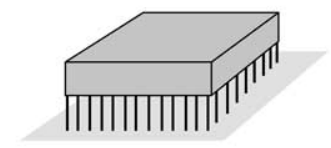

b
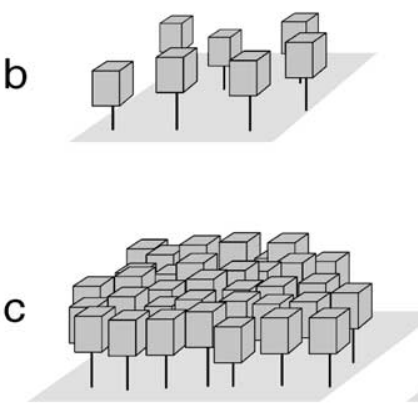
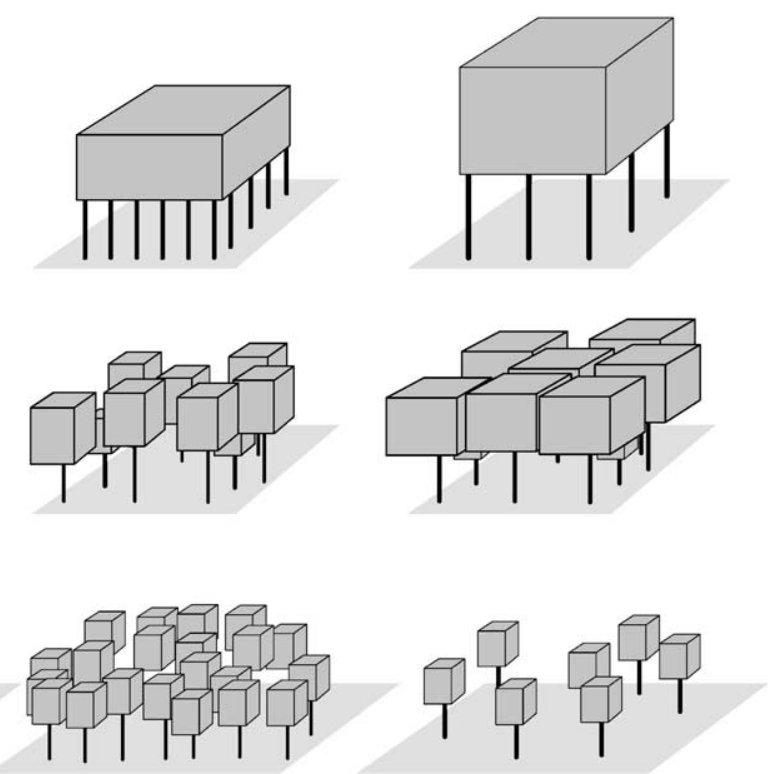

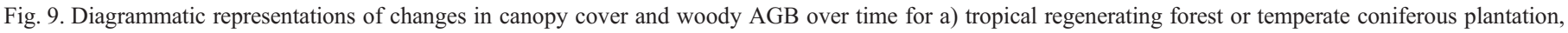

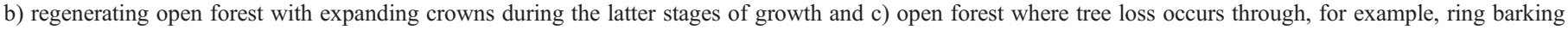
or dieback.

the scene. For example, the Japanese Earth Resources Satellite (JERS-1) SAR observed at an incidence angle of $35^{\circ}$ and within these images, incidence angle effects are minimal. Even so, the incidence angle at which spaceborne sensors observe needs to be considered when designing sensors and developing or using algorithms for specific applications. For example, Rignot et al. (1994) noted that estimates of AGB generated using empirical relationships with L-band SAR data over a small incidence angle range will be too low when used with data acquired at large incidence angles and vice versa. In this study, incidence angle effects were not corrected or compensated for when establishing the relationships between LiDARderived AGB and SAR backscattering coefficient, and this allowed the significance of this parameter for retrieval of AGB to be highlighted.

Within the AIRSAR data, a lower dynamic range was generally observed at smaller incidence angles. This can be attributed to reductions in surface scattering and variations in the contribution of different scattering mechanisms (Le Toan et al., 1992). At smaller incidence angles, surface scattering from non-forested areas occurs but becomes more prominent (particularly at higher frequencies) as the incidence angle increases and hence a lower backscatter is returned (Brown et al., 2003). By contrast, the backscatter from the canopy volume remains relatively similar regardless of incidence angle, although is slightly enhanced at higher angles because of greater double bounce interactions (see Fig. 8). For this reason, the difference in backscatter between the forest and non-forest areas (i.e., the dynamic range) is greater at larger incidence angles, as indicated in Table 7. Similar observations were also reported by Moghaddam et al. (1994) for boreal forests.

At C-band, the angular dependence of the backscattering coefficient is greatest and noticeable differences over non- forested areas were observed, particularly at $\mathrm{HH}$ and $\mathrm{VV}$ polarizations. At $\mathrm{HV}$, the variation in backscatter with incidence angle was less apparent as saturation occurs at relatively low levels of biomass and the increased volume of leaves and smaller branches attenuating the microwaves at larger incidence angles does not therefore lead to an increase in backscatter (Kellndorger et al., 2004). At L-band and P-band, double bounce scattering tends to dominate at larger incidence angles, particularly within more open forests, and the enhancement of HH backscatter from the forest (Lucas et al., 2004) together with reductions in surface scattering lead to a large dynamic range. The enhancement of the backscattering coefficient from forests at $\mathrm{HV}$ polarizations with increasing incidence angle is also evident and can be attributed to the greater interaction with branches (through volume scattering; Moghaddam et al., 1994).

\subsection{Retrieval of $A G B$ from $S A R$}

Saturation of SAR backscatter has long been recognised as a limitation of SAR for the retrieval of AGB and is often provided as reason for not adopting this technology for operational mapping purposes (Le Toan et al., 2004; Lucas et al., 2000). Indeed, Imhoff (1995b) concluded that SAR data could only be used to quantify the biomass of less than $25 \%$, $37 \%$ and $62 \%$ of the world's forests at C-band, L-band and Pband, respectively as a consequence of saturation. To evaluate this limitation for the Injune study area, an overview of AGB distributions was first undertaken based on the LiDAR-derived AGB estimates for the 4500 PSUs. Then, using the average saturation levels determined (Table 5) for observations at the larger incidence angles of $45.8-50.5^{\circ}$ and $57.2-59.9^{\circ}$, the percentage of the study area for which AGB could be retrieved using the empirical relationships were estimated. 


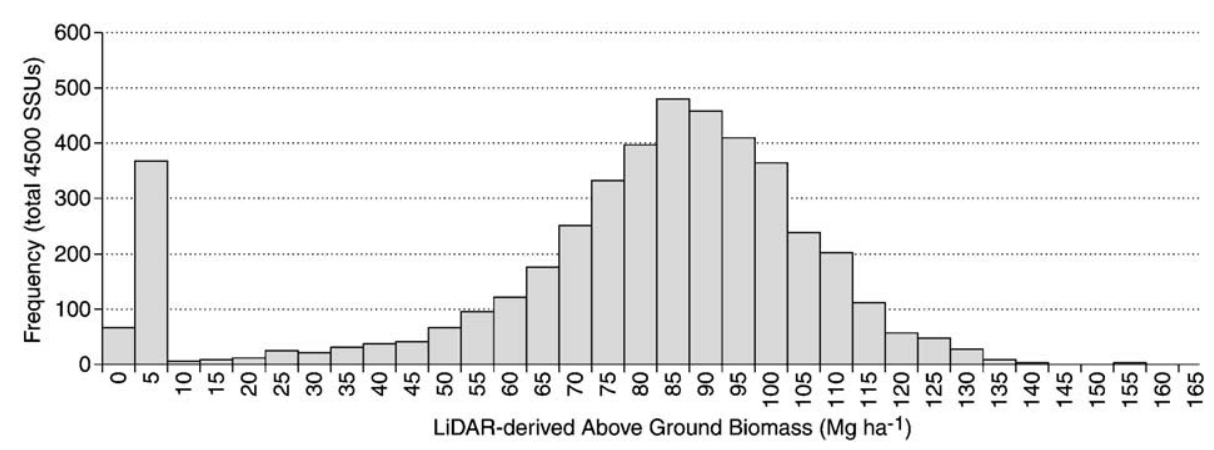

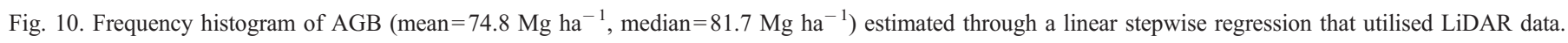

\subsubsection{Landscape distribution of $A G B$}

A summary of the distribution of AGB across the PSU grid is provided in Fig. 10 and Table 8 and, based on the sampling strategy, is assumed to be representative of the landscape as a whole. Within the area surveyed, $84.2 \%$ of the forests (including sparse or non-forested areas with $<20 \mathrm{Mg} \mathrm{ha}^{-1}$ ) supported an AGB of $<100 \mathrm{Mg} \mathrm{ha}^{-1}$ with the remaining $15.8 \%$ supporting an AGB ranging from 100 to $164 \mathrm{Mg} \mathrm{ha}^{-1}$. The mean and median biomass was 74.8 and $81.7 \mathrm{Mg} \mathrm{ha}^{-1}$, respectively. These estimates are comparable with those produced by the Australian Greenhouse Office (2000), Burrows et al. (2002), and Barrett et al. (2001) for the region. Based on the interpretation of the LSP, the composition of the species also varied with biomass. Specifically, for forests up to $10 \mathrm{Mg} \mathrm{ha}^{-1}$, A. harpophylla was commonplace (regeneration following land clearing). However, within the $10-50 \mathrm{Mg} \mathrm{ha}^{-1}$ category, a range of Callitris and Eucalyptus dominated species associations occurred with sub-dominant occurrence of E. melanaphloia, $E$. populnea and other Eucalyptus species. Between 50 and 100 $\mathrm{Mg} \mathrm{ha}^{-1}$, associations of C. glaucophylla with E. melanaphloia but also A. leiocarpa, E. dealbata var. chloroclada and Eucalyptus species capable of attaining a larger size were most frequent. Up to $165 \mathrm{Mg} \mathrm{ha}^{-1}$, the prevalence of associations dominated by Angophora species became more apparent.

\subsubsection{AGB mapping using $S A R$ data}

For an incidence angle of between $45.8-50.5^{\circ}$, the AGB could only be estimated for a maximum of $46 \%$ of the area using L-band HV data but for less than $30 \%$ of the area using all other channels (Table 9). Using the higher incidence angle, AGB could be estimated for between $46 \%$ and $57 \%$ of the area

Table 8

Percentage and cumulative percentage distribution of biomass within the 4500 PSUs

\begin{tabular}{lrcc}
\hline $\begin{array}{l}\text { Biomass range } \\
\left(\mathrm{Mg} \mathrm{ha}-{ }^{1}\right)\end{array}$ & No. of SSUs & Percentage & $\begin{array}{l}\text { Cumulative } \\
\text { percentage }\end{array}$ \\
\hline$<10$ & 443 & 9.8 & 9.8 \\
$10-25$ & 49 & 1.1 & 10.9 \\
$25-50$ & 204 & 4.5 & 15.5 \\
$50-75$ & 652 & 14.5 & 30.0 \\
$75-100$ & 2442 & 54.3 & 84.2 \\
$100-125$ & 661 & 14.7 & 98.9 \\
$125-150$ & 44 & 1.0 & 99.9 \\
$>150$ & 5 & 0.1 & 100.0 \\
\hline
\end{tabular}

using L-band $\mathrm{HV}$ and also P-band $\mathrm{HH}$ and $\mathrm{HV}$ data. It should be emphasised that these estimates are applicable to the study area only and would differ for areas where AGB is below the saturation level (e.g., those dominated by regrowth).

\subsubsection{Optimal channels for retrieval}

Overall, retrieval of AGB is best achieved using SAR backscatter data acquired at a high incidence angle, regardless of frequency and polarization, primarily because of the greater dynamic range of the data. As the frequency decreases (i.e., towards L-band and P-band), VV polarization data are less suited for retrieving biomass compared to $\mathrm{HH}$ and $\mathrm{HV}$ data. If using single channel SAR data alone to retrieve biomass, the cross-pol (HV) data at lower frequencies are perhaps optimal, particularly at these lower frequencies where there appears to be a lesser dependence on incidence angle and the range of data is greater compared to other polarizations. However, HH polarizations, particularly at moderate to high incidence angles, are also appropriate, although the range is often slightly reduced. The use of L-band HV data acquired at an incidence angle approaching or above $45^{\circ}$ is considered to be optimal for AGB estimation, as the saturation is relatively high $\left(>80 \mathrm{Mg} \mathrm{ha}^{-1}\right)$ and the dynamic range of these data is greater compared to copolarized data. Le Toan et al. (2004) also indicated that L-band $\mathrm{HV}$ exhibited greater sensitivity to biomass compared to $\mathrm{HH}$ and VV polarizations and was also the least affected by forest type and ground surface conditions, as observed in this study. Even so, L-band HV data are generally less well calibrated than the co-polarized data, and statistical noise on the signal suggests that detectable change is $\sim 1 \mathrm{~dB}$, with this corresponding to a resolution of about $10 \mathrm{Mg} \mathrm{ha}^{-1}$ in the range $0-50 \mathrm{Mg} \mathrm{ha}^{-1}(\mathrm{Le}$

Table 9

Percentage of the 4500s PSUs for which AGB can be retrieved using different SAR channels based on saturation levels at difference incidence angles

\begin{tabular}{lllll}
\hline & $\begin{array}{l}\text { Saturation level } \\
45.8-50.5^{\circ}\end{array}$ & $\begin{array}{l}\text { \% of PSU grid } \\
\text { (approx) }\end{array}$ & $\begin{array}{l}\text { Saturation level } \\
57.2-59.9^{\circ}\end{array}$ & $\begin{array}{l}\text { \% of PSU } \\
\text { grid (approx) }\end{array}$ \\
\hline C HH & 45 & 14 & 35 & 12 \\
C VV & 42 & 14 & 45 & 14 \\
C HV & 58 & 20 & 50 & 16 \\
L HH & 63 & 24 & 70 & 24 \\
L VV & 67 & 30 & 75 & 37 \\
L HV & 82 & 46 & 85 & 57 \\
P HH & 60 & 20 & 80 & 46 \\
P VV & 55 & 18 & 68 & 30 \\
P HV & 72 & 30 & 80 & 46 \\
\hline
\end{tabular}


Toan et al., 2004; Tansey et al., 2004). Although P-band data (particularly HV polarizations) are generally regarded as more suitable for AGB estimation because of the higher levels of saturation (Le Toan et al., 2004), the scattering behaviour in the more open forests and particularly those that are structurally complex is generally less predictable. This is also evidenced by modelling studies (Lucas et al., 2004) which suggest more complex interactions with different structural components, particularly within the higher biomass forests.

Forward modelling of SAR backscatter from these forests (Lucas et al., 2004) suggests that the relationships observed between SAR backscatter and AGB are due to differential interaction of microwaves with different components (leaves, branches and trunks) of the forest and inherent relationships between these components and the total AGB. For example, Lband $\mathrm{HH}$ and $\mathrm{HV}$ microwaves interact largely with the trunks (through double bounce scattering) and branches (through volume scattering), respectively. Within structurally homogeneous forests (e.g., those dominated by Callitris or Eucalpytus species), retrieval of AGB using either channel will be more reliable as the relationship between the biomass of these components and the total is more consistent across the stand. However, where a mix of structures occurs, such as in stands containing excurrent or decurrent forms or trees at different stages of regeneration and degradation, greater scatter in the relationship will be typical and the accuracy of AGB retrieval is likely to be compromised. Within the study area, over 270 different forest descriptions (based on species dominance and canopy structure) were generated from the interpretation of LSP, with many stands containing both excurrent and decurrent forms. The wide range of structures existing within the forests therefore accounts for the observed variability in the SAR backscatter across the study area. As a result of this complex structure, the retrieval of $\mathrm{AGB}$ is compromised and the establishment of community-specific relationships for improving retrieval is also unlikely. For these same reasons, discrimination of forest communities and structures using SAR data alone is limited. Further research is nevertheless required to better understand the complexity of microwave interaction within such forests such that SAR data can be used more effectively for forest characterisation.

\subsection{Past, present and future sensors for AGB estimation}

The adoption of SAR data for operational mapping of AGB is dependent upon their availability of sensors and the outcome of this research has implications for the design and/ or programming of single or dual polarization spaceborne SAR data for forest AGB retrieval. From this analysis, the potential of historical, active and future spaceborne sensors for routinely quantifying the AGB of open forests can be assessed. To date, spaceborne SAR have only routinely acquired data at C-band, with the European Resources Satellites ERS$1 / 2$ SAR, RADARSAT and ENVISAT ASAR observing at $\mathrm{VV}, \mathrm{HH}$ and dual polarizations ( $\mathrm{HH}, \mathrm{VV}$ and/or $\mathrm{HV}$ ), respectively, and L-band where the Japanese Earth Resources Satellite (JERS-1) SAR acquired data at $\mathrm{HH}$ polarization only (Table 10). Based on this study, the incidence angles (and, in some cases, polarizations) at which these sensors operate is suboptimal and it is evident why success in the routine retrieval of AGB has been quite limited (Lucas et al., 2000).

Of the currently operating spaceborne SAR, ENVISAT ASAR data are best suited for the estimation of biomass (up to about $50 \mathrm{Mg} \mathrm{ha}^{-1}$ ) for forests typical to the study area, although perform a similar role as FPC estimates derived routinely from Landsat sensor data (Danaher et al., 2004. Indeed, the close correspondence between C-band HV data and FPC (Cronin et al., 2005) suggests that these data might provide near equivalent information. The best future opportunity for regional estimation of AGB therefore rests with the forthcoming Japanese Advanced Land Observing Satellite (ALOS) Phase Arrayed L-band SAR (PALSAR), which is due to for launch in 2006. This satellite sensor will provide global L-band data at $\mathrm{HH}$ and $\mathrm{HV}$ polarizations and incidence angles of $41^{\circ}$. Although a larger incidence angle would provide better estimates, it is anticipated that reasonable estimates of AGB are likely to be obtained with the ALOS PALSAR. The greater dynamic range of the L-band HV data are anticipated also to render these data more sensitive to the differing levels of AGB. The combination of L-band HH and HV data, and integration with either FPC or ENVISAR ASAR data, may also facilitate estimation of component (i.e., trunk, large branch and leaf/small branch) biomass due to differential interaction of microwaves (Lucas et al., 2004). Although these data will need to be evaluated, the outcomes of the research reported in this paper suggest their potential for retrieving AGB. As the forests of the Injune study area are typical, both in terms of floristics, structure and biomass, to those across large areas of Queensland and, indeed, Australia, it is anticipated that the use and integration of these data will have wider applications for national carbon accounting (Barrett et al., 2001; Henry et al.,

Table 10

Sensor specifications of spaceborne SAR sensors (adapted from Bergen \& Dobson, 1999; Le Toan et al., 2004)

\begin{tabular}{|c|c|c|c|c|c|c|c|}
\hline Agency & Satellite & Year & Band & Polarisation & Incidence angle & Resolution & Swath \\
\hline ESA & ERS-1 & $1991-2000$ & $\mathrm{C}$ & VV & $23^{\circ}$ & $30 \mathrm{~m}$ & $100 \mathrm{~km}$ \\
\hline ESA & ERS-2 & 1995 & $\mathrm{C}$ & VV & $23^{\circ}$ & $30 \mathrm{~m}$ & $100 \mathrm{~km}$ \\
\hline JAXA & JERS-1 & $1992-1998$ & $\mathrm{~L}$ & $\mathrm{HH}$ & $35^{\circ}$ & $30 \mathrm{~m}$ & $100 \mathrm{~km}$ \\
\hline CSA & RADARSAT & $1991-$ & $\mathrm{C}$ & $\mathrm{HH}$ & Multi & $30 \mathrm{~m}$ & $100 \mathrm{~km}$ \\
\hline ESA & ENVISAT & $2002-$ & $\mathrm{C}$ & HH VV HV & Multi & $15-45 \mathrm{~m}$ & $100-1000 \mathrm{~km}$ \\
\hline JAXA & $\operatorname{ALOS}^{1}$ & $2005-$ & $\mathrm{L}$ & HH VV HV & Multi & $50 \mathrm{~m}$ & $40-350 \mathrm{~km}$ \\
\hline
\end{tabular}

${ }^{1}$ Incidence angle of $41^{\circ}$ for dual pol ( $\mathrm{HH}$ and $\mathrm{HV}$ ) mode. 
2002), sustainable management of ecosystems and conservation of biodiversity (Faith, 2003).

\section{Conclusions}

The research has demonstrated the potential of SAR for the retrieval of forest AGB through scaling-up of plot-based estimates to the larger area using LiDAR data and subsequently establishing quantitative relationships between AGB and SAR backscatter at different frequencies, polarizations and incidence angles.

The estimation of AGB from LiDAR integrated measures of vegetation height, canopy cover and the vertical distribution and density of vegetation returns. The approach was successful in this environment as significant proportion of returns were from the ground surface and canopy because of the relatively openness of the forest and sparseness of the overstorey. The step-wise linear regression considered a wide range of forest structural types and the resulting landscape estimates of AGB were appropriate to the study area and comparable with previous estimates.

Saturation of AIRSAR backscatter data at all frequencies and polarizations was observed. However, C-band data, particularly at $\mathrm{HV}$ polarization, saturated at a higher (over $\sim 55 \mathrm{Mg} \mathrm{ha}^{-1}$ ) AGB level compared to that typically observed for closed forests, suggesting that these data are useful for estimating AGB in open forest situations. This higher level of saturation was explained by the increase in crown cover with AGB, particularly during the later stages of growth and for decurrent forms. The strength of the relationship between SAR backscatter and AGB varied with incidence angle, partly because increased surface scattering away from the sensor resulted in lower returns from the ground surface a greater dynamic range of the data.

For mapping AGB across the more open forests of Australia, the use of L-band HV data from the ALOS PALSAR should be considered. These data should allow the AGB of large areas of forest to be estimated, particularly as many support an AGB below the saturation level of $\sim 80 \mathrm{Mg} \mathrm{ha}^{-1}$. The acquisition of data at $41^{\circ}$ should also allow acquisition of data across a reasonable dynamic range, thereby allowing different levels of AGB to be separated. However, given that different SAR and also optical channels can provide information on different components of the forest canopy, the integration of these datasets for better estimation of $\mathrm{AGB}$ needs to be considered also for operational purposes.

\section{Acknowledgements}

The authors thank the Australian Research Council (ARC) under their SPIRT Program (for a grant to the University of New Wales), the Queensland Department of Natural Resources and Mines (QDNR and M), Bureau of Rural Sciences (BRS), the Australian Greenhouse Office and the Cooperative Research Centre (CRC) for Greenhouse Accounting for collectively funding this research, the Queensland Department of Primary Industries (QDPI) Tropical Beef Centre and QDPI for assisting with destructive harvesting and the NASA Jet Propulsion Laboratory for acquiring the AIRSAR data.

\section{References}

Austin, J. M., Mackey, B. G., \& Van Niel, K. P. (2003). Estimating forest biomass using satellite radar: an exploratory study in a temperate Australian Eucalyptus forest. Forest Ecology and Management, 176, 575-583.

Australian Greenhouse Office (2000). National greenhouse gas inventory: Land use change and forestry sector 1990-1999. Canberra: Commonwealth of Australia.

Barrett, D. J., Galbally, I. E., \& Graetz, R. D. (2001). Quantifying uncertainty in estimates of $\mathrm{C}$ emissions from above ground biomass due to historical land-use change to cropping in Australia. Global Change Biology, 7, $883-902$.

Baskerville, G. L. (1972). Use of logarithmic regression in the estimation of plant biomass. Canadian Journal of Forestry, 2, 49-53.

Bergen, K. M., \& Dobson, M. C. (1999). Integration of remotely sensed data in modelling and mapping of forest biomass and net primary production. Ecological Modelling, 122, 257-274

Beauchamp, J. J., \& Olson, J. S. (1973). Corrections for bias in regression estimates after logarithmic transformation. Ecology, 54, 1403-1407.

Brown, S. C. M., Quegan, S., Morrison, K., Bennet, J. C., \& Cookmartin, G. (2003). High-resolution measurements of scattering in wheat canopiesImplications for crop parameter retrieval. IEEE Transactions on Geoscience and Remote Sensing, 41, 1602-1609.

Bureau of Meteorology. (2004). URL: http://www.bom.gov.au (Accessed April 2004).

Bureau of Rural Sciences (BRS). (2003). Australia's Forests at a Glance, BRS, Canberra, Australia (p. 68)

Burrows, W. H., Henry, B. K., Back, P. V., Hoffman, M. B., Tait, L. J., Anderson, E. R., et al. (2002). Growth and carbon stock change in eucalypt woodland stands in north-east Australia: Ecological and greenhouse sink implications. Global Change Biology, 8, 769-784.

Burrows, W. H., Hoffman, M. B., Compton, J. F., \& Back, P. V. (2001). Allometric relationships and community biomass stocks in White Cypress Pine (Callitris glaucophylla) and associated eucalpyts of the Carnarvon area, central Queensland. National Carbon Accounting System (NCAS) Technical Report, 33.

Burrows, W. H., Hoffman, M. B., Compton, J. F., Back, P. V., \& Tait, L. J. (2000). Allometric relationships and community biomass estimates for some dominant eucalyptus in central Queensland woodlands. Australian Journal of Botany, 48, 707-714.

Carnahan, J. A. (1990). Vegetation. Atlas of Australian Resources. Australian Surveying and Land Information Group, vol. 6 Third Series. Canberra, Australia: Dept of Administrative Services.

Cronin, N., Lucas, R. M., \& Lee, A. (2005). Integration of radar and landsatderived foliage projected cover data for forest community mapping (in progress).

Danaher, T. J., Armston, J. D., \& Collett, L. J. (2004). A regression approach to mapping woody foliage projective cover in Queensland with Landsat data. International Geoscience and Remote Sensing Symposium (IGARSS), Anchorage, Alaska, September 2004.

Dobson, M. C., Ulaby, F. T., Le Toan, T., Beaudoin, A., Kasischke, E. S., \& Christensen, N. (1992). Dependence of radar backscatter on coniferous forest biomass. IEEE Transactions on Geoscience and Remote Sensing, 30, $412-415$.

Dobson, M. C., Ulaby, F. T., Pierce, L. E., Sharik, T. L., Bergen, K. M., Kellndorfer, J., et al. (1995). Estimation of forest biophysical characteristics in northern Michigan with SIR-C/X-SAR. IEEE Transactions on Geoscience and Remote Sensing, 33, 8877-8895.

dos Santos, J. R., Freitas, C. C., Aruajo, L. S., Dutra, L. V., Mura, J. C., Gama, F. F., et al. (2003). Airborne P-band SAR applied to above ground biomass studies in the Brazilian tropical forest. Remote Sensing of Environment, 87, $482-493$.

Dowling, R., \& Accad, A. (2003). Vegetation classification of the riparian zone along the Brisbane River, Queensland, Australia using Light Detection and Ranging (LiDAR) data and forward looking digital video. Canadian Journal of Remote Sensing, 29, 556-563.

McGuinness, D., Eamus, K., \& Burrows, W. H. (2001). Review of allometric relationships for estimating woody biomass for Queensland, the Northern 
Territory and Western Australia. Technical Report, vol. 5 a . Canberra, ACT, Australia: Australian Greenhouse Office (AGO) 64 pp.

Fairfax, R. J., \& Fensham, R. J. (2000). The effect of exotic pasture development on floristic diversity in central Queensland, Australia. Biological Conservation, 94, 11-21.

Faith, D. P. (2003). Environment diversity (ED) as surrogate information for species level diversity. Ecography, 26, 374-379.

Foody, G. M., Cutler, M. E., McMorrow, J., Pelz, D., Tangki, H., Boyd, D., et al. (2001). Mapping the biomass of Bornean tropical rainforests from remotely sensed data. Global Ecology and Biogeography, 10, 379-387.

Harrington, G. (1979). Estimation of above ground biomass of trees and shrubs in Eucalyptus populnea (F. Muell). Woodland by regression of mass on trunk diameter and plant height. Australian Journal of Botany, 2, 135-143.

Harris, M. R., Lamb, D., \& Erskine, P. D. (2003). An investigation into the possible inhibitory effects of white cypress pine (Callitris glaucophylla) litter on the germination and growth of associated ground cover species. Australian Journal of Botany, 51, 93-102.

Henry, B. K., Danaher, T., McKeon, G. M., \& Burrows, W. H. (2002). A review of the potential role of greenhouse gas abatement in native vegetation management in Queensland rangelands. Rangeland Journal, 24, 112-132.

Hoekman, D. H., \& Quiñones, M. J. (2000). Land cover type and biomass classification using AirSAR data for evaluation of monitoring scenarios in the Colombian Amazon. IEEE Transactions on Geoscience and Remote Sensing, 38, 685-696.

Holmgren, J., Nilsson, M., \& Olsson, H. (2003). Estimation of tree height and stem volume on plots-using airborne laser scanning. Forest Science, 49, $419-428$.

Hyyppa, J., Kelle, O., Lehikoinen, M., \& Inkinen, M. (2001). A segmentationbased method to retrieve stem volume estimates from 3-D tree height models produced by laser scanners. IEEE Transactions on Geoscience and Remote Sensing, 39, 969-975.

Imhoff, M. L. (1995a). A theoretical analysis of the effect of forest structure on Synthetic Aperture Radar backscatter and the remote sensing of biomass. IEEE Transactions on Geoscience and Remote Sensing, 33, 341-352.

Imhoff, M. L. (1995b). Radar backscatter and biomass saturation: Ramifications for global biomass inventory. IEEE Transactions on Geoscience and Remote Sensing, 33, 511-518.

Jerez, M., Dean, T. J., Cao, Q. V., \& Roberts, S. D. (2005). Describing leaf area distribution in loblolly pine trees with Johnson's SB function. Forest Science, 51, 93-101.

Jones, K. L. (2000). Aerial photography interpretation for the Injune Remote Sensing Sampling Strategy. Forest Ecosystem Research and Assessment Technical Report, vol. 00129. Brisbane: Queensland Department of Natural Resources.

Kasischke, E. S., Melack, J. M., \& Dobson, M. C. (1997). The use of imaging radars for ecological applications-A review. Remote Sensing of Environment, 59, 141- 156 .

Kellndorger, J., Walker, W., Pierce, L., Dobson, C., Fites, J. A., Hunsaker, C., et al. (2004). Vegetation height estimation from Shuttle Radar Topographic Mission and National Elevation Datasets. Remote Sensing of Environment, 93, 339-358.

Le Toan, T., Beaudoin, A., Riom, J., \& Guyon, D. (1992). Relating forest biomass to SAR data. IEEE Transactions Geoscience and Remote Sensing, 30, $403-411$.

Le Toan, T., Quegan, S., Woodward, I., Mark, L., Nicolas, D., \& Ghislain, P. (2004). Relating radar remote sensing of biomass to modelling of forest carbon budgets. Climatic Change, 67, 379-402.

Liang, P., Moghaddam, M., Pierce, L., \& Lucas, R. M. (2005). Radar backscatter model for multi-layer mixed species forests. IEEE Transactions on Geoscience and Remote Sensing, 43(11), 2612-2626.

Lim, K. S., \& Treitz, P. M. (2004). Estimation of above ground forest biomass from airborne discrete return laser scanner data using canopy-based quantile estimators. Scandinavian Journal of Forest Research, 19, 558-570.

Lim, K., Treitz, P., Wulder, M., St-Onge, B., \& Flood, M. (2003). LiDAR remote sensing of forest structure. Progress in Physical Geography, 27, 88-106.

Lucas, R. M., Honzak, M., do Amaral, I., Curran, P. J., \& Foody, G. M. (2002). Forest regeneration on abandoned clearances in central Amazonia. International Journal of Remote Sensing, 23, 965-988.
Lucas, R. M., Milne, A. K., Cronin, N., Witte, C., \& Denham, R. (2000). The potential of Synthetic Aperature Radar (SAR) data for quantifying the above ground biomass of Australia's woodlands. Rangeland Journal, 22, $124-140$.

Lucas, R. M., Moghaddam, M., \& Cronin, N. (2004). Microwave scattering from mixed species woodlands, central Queensland, Australia. IEEE Transactions on Geoscience and Remote Sensing, 42, 2141-2159.

Lucas, R. M., Tickle, P., Witte, C., \& Milne, A. K. (2001). Development of multistage procedures for quantifying the biomass, structure and community composition of Australian woodlands using polarimetric radar and optical data. Proceedings, IGARSS symposium, Sydney, Australia (CD).

Luckman, A., Baker, J., Kuplich, T. M., Yanasse, C. C. F., \& Frery, A. C. (1997). A study of the relationship between radar backscatter and regenerating tropical forest biomass for spaceborne SAR instruments. Remote Sensing of Environment, 60, 1-13.

Magnussen, S., \& Boudewyn, P. (1998). Derivations of stand heights from airborne laser scanner data with canopy-based quantile estimators. Canadian Journal of Forest Research-Revue Canadienne De Recherche Forestiere, 28, 1016-1031.

McDonald, R. C., Isbell, J. G., Speight, J. G., Walker, J., \& Hopkins, M. S. (1998). Australian soil and land survey field handbook (Second edition). Commonwealth Dept of Primary Industries and Energy and CSIRO. 190 pp.

Means, J. E., Acker, S. A., Harding, D. A., Blair, B. J., Lefsky, M. A., Cohen, W. B., et al. (1999). Use of large footprint scanning airborne LIDAR to estimate forest stand characteristics in the western Cascades of Oregon. Remote Sensing of Environment, 67, 298-308.

Moghaddam, M., Durden, S., \& Zebker, H. (1994). Radar measurement of forested areas during OTTER. Remote Sensing of Environment, 47, 154-166.

Ranson, K. J., \& Sun, G. (1994). Mapping biomass of a northern forest using multifrequency SAR data. IEEE Transactions on Geoscience and Remote Sensing, 32, 388-396.

Rauste, Y., Hame, T., Pulliainen, J., Heiska, K., \& Hallikainen, M. (1994). Radar based forest biomass estimation. International Journal of Remote Sensing, 15(14), 2797-2808.

Rignot, E., Way, J., Williams, C., \& Viereck, L. (1994). Radar estimates of above ground biomass in boreal forests of interior Alaska. IEEE Transactions on Geoscience and Remote Sensing, 32, 1117-1124.

Roecker, E. B. (1991). Prediction error and it estimation for sub-set-selected models. Technometrics, 33, 459-468.

Rosenqvist, A., Milne, A. K., Lucas, R. M., Imhoff, M., \& Dobson, C. (2003). A review of remote sensing technology in support of the Kyoto Protocol. Environment, Science and Policy, 6, 441-455.

SLATS. (2003). Land Cover Change in Queensland 1999-2001. The Statewide Landcover and Trees Study (SLATS) report (pp. 44-67). Natural Resource Precinct, 80 Meiers Road, Indooroopilly, Queensland 4068, Australia: Queensland Department of Natural Resources and Mines. 78 pp.

Specht, R. L. (1970). Vegetation. In G. W. Leeper (Ed.), The Australian Environ (Fourth edition). Melbourne: CSIRO- Melbourne University Press.

Specht, R. L., \& Specht, A. (1999). Australian plant communities: Dynamics of structure, growth and biodiversity. ACT, Australia: Oxford University Press.

Tansey, K. T., Luckman, A. J., Skinner, L., Baltzer, H., \& Strozzi, T. (2004). Classification of forest volume resources using ERS tandem coherence and JERS backscatter data. International Journal of Remote Sensing, 25, $751-768$.

Tomlinson, J. R., Bolstad, P. V., \& Cohen, W. B. (1999). Coordinating methodologies for scaling landcover classifications from site-specific to global: Steps towards validating global map products. Remote Sensing of Environment, 70, 16-28.

Turner, B., Wells, K., Bauhus, J., Carey, G., Brack, C., \& Kanowski, P. (1999). Woody biomass: Methods for estimating change. National Carbon Accounting System (NCAS) Technical Report, vol. 3. ACT, Australia: The Australian Greenhouse Office. Canberra.

Van Zyl, J. J., Zebker, H. A., \& Elachi, C. (1987). Imaging radar polarization signatures. Theory and observation. Radio Science, 22, 529-543.

Zebker, H. A., Van Zyl, J. J., \& Held, D. N. (1987). Imaging radar polarimetry from wave synthesis. Journal of Geophysical Research, 92, 683-701. 